\title{
Trace determination of safranin $O$ dye using ultrasound assisted dispersive solid-phase micro extraction: Artificial neural network-genetic algorithm and response surface methodology
}

\author{
Ebrahim Alipanahpour Dil a , Mehrorang Ghaedi ${ }^{*}$, , Arash Asfaram ${ }^{a}$, Fatemeh Mehrabi ${ }^{\text {b }}$ Ali Akbar Bazrafshana, \\ Abdol Mohammad Ghaedi ${ }^{\mathrm{b}}$ \\ ${ }^{a}$ Chemistry Department, Yasouj University, Yasouj 75918-74831, Iran. \\ ${ }^{b}$ Chemistry Department, Gachsaran Branch, Islamic Azad University, Gachsaran, Iran.
}

\begin{abstract}
In this study, ultrasound assisted dispersive solid-phase micro extraction combined with spectrophotometry (USADSPME-UV) method based on activated carbon modified with $\mathrm{Fe}_{2} \mathrm{O}_{3}$ nanoparticles $\left(\mathrm{Fe}_{2} \mathrm{O}_{3}\right.$-NPs-AC) was developed for pre-concentration and determination of safranin $\mathrm{O}(\mathrm{SO})$. It is known that the efficiency of USA-DSPME-UV method may be affected by $\mathrm{pH}$, amount of adsorbent, ultrasound time and eluent volume and the extent and magnitude of their contribution on response (in term of main and interaction part) was studied by using central composite design (CCD) and artificial neural network-genetic algorithms (ANN-GA). Accordingly by adjustment of experimental conditions suggested by ANN-GA at $\mathrm{pH} 6.5,1.1 \mathrm{mg}$ of adsorbent, $10 \mathrm{~min}$ ultrasound and $150 \mu \mathrm{L}$ of eluent volume led to achievement of best operation performance like low LOD $\left(6.3 \mathrm{ng} \mathrm{mL}^{-1}\right)$ and LOQ $(17.5 \mathrm{ng} \mathrm{mL}$ ${ }^{1}$ ) in the range of $25-3500 \mathrm{ng} \mathrm{mL}^{-1}$. In following stage, the SO content in real water and wastewater samples with recoveries between $93.27-99.41 \%$ with RSD lower than $3 \%$ was successfully determined.
\end{abstract}

Keywords: Artificial Neural Network; Central composite design, Genetic algorithms; Safranin O; Ultrasound assisted dispersive solid-phase micro extraction.

\section{Introduction}

* Corresponding author at: Tel.: +98 741 2223048; fax: +98 7412223048.

E-mail address: m_ghaedi@mail.yu.ac.ir; m_ghaedi@yahoo.com

(C) 2016. This manuscript version is made available under the Elsevier user license http://www.elsevier.com/open-access/userlicense/1.0/ 
Huge content of contaminant in different industrial waste water via their following entrance to aqueous media led to serious the damaging their quality of in subsequently destroy health of living things [1-3]. Some of these contaminants due to their natural toxicity, carcinogenic or mutagenic property and also their high bioaccumulation efficiency received special attention even at very low concentrations [4-6]. Recently, match attention was devoted to quality of environmental, which encourage the researchers to design appropriate control procedure to reduce health hazards [7-9].

Safranin O (SO) used as food additive for generation of colour candies and cookies, textile industries, leather, paper as well as in researches related to histology, textile, cytology and bacteriology [10]. While this material is not toxic with hazardous nature in comparison to other respective ones, its permanente exposure and consumption led to creation of such as cornea and conjunctiva in human and rabbit eyes and also cause skin and respiratory tract irritation [11].

Therefore, there is a need for an accurate and precise method for determining these organic pollutant in various matrices such as organism, atmosphere, water, and soil to grasp the dynamics of toxic compounds in various environments.

Application of ultrasound irradiation accelerate chemical process via production of acoustic cavitation that achieved by the propagation of pressure wave through a liquid [12]. Ultrasound energy improve the mass transfer through convection pathway and probable activation of reactive surface that is emerged from physical phenomena such as micro-streaming and turbulence, acoustic (or shock) waves and microjets [13]. Shock waves have the potential of creating microscopic turbulence within interfacial films surrounding neighbor solid particles. Ultrasonic radiation is powerful tools to intensify the mass transfer (adsorption and desorption) process by various known and probable mechanism [14-17].

Ultrasound assisted dispersive solid-phase microextraction (USA-DSPME-UV) is a sample handling technique characterized as being a real non-solvent technique [18]. The choice of extracting phase is essential in USADSPME-UV to achieve selective and efficient extraction of the analytes to be determined [19]. USA-SPME-UV can be considered as a very green sample preparation technique, because of its solvent-free characteristics [3, 17]. USADSPME-UV allows pre-concentrating the analytes in an easy way without the need for solvent evaporation after the extraction process, as typically occurs with conventional extraction techniques [20,21]. The total removal of organic solvents for sample preparation avoids or minimizes the waste generation derived from the sample preparation step. 
Moreover, it can be used for the extraction and preconcentration of target analytes present in very small samples because of the convenient dimensions of the USA-DSPME-UV system [22, 23].

In application of extraction process, it is crucial to improve process efficiency, reduce operational cost and time to minimum and take into account the most important factors, what can be achieved by applying the optimization techniques such as response surface methodology (RSM) and artificial neural network-genetic algorithm (ANN-GA) $[24,25]$.

Response surface methodology (RSM) is the collection of experimental design techniques that uses statistical and mathematical methods for designing the experiments, evaluating the effects of several factors, and achieving the optimum conditions for desirable responses with a limited number of planned experiments. RSM consists of an adequate functional relationship between a response of interest and a number of associated control variables. The purpose of RSM method is to find the optimum response and realize how the response changes in a given direction by modulating the design variables $[2,26,27]$.

The most popular artificial neural network (ANN) architecture is associated with the common multi-layered perceptron comprised of input, hidden and output layers, and different numbers of neurons in each layer. As ANN models are exclusively data-based, it is not possible to guarantee their smoothness in the optimization phase. Hence, the conventional gradient-based optimization methods, which require a continuous, differentiable and, more importantly, smooth objective function, in general may not be used efficiently to optimize the function learned by ANN. The optimization of ANN parameters can be improved using GA, a stochastic global search algorithm, achieving better performances. GA simulate the survival-of-the-fittest principle of nature while searching for an objective function that helps in its natural optimization. GA use string coding of variables for dividing the search space into discrete ones, which further helps in searching for global optimum in the entire solution space. GA are used for optimization based on weights and biases obtained ANN. The genetic algorithm is applicable to solve a variety of optimization problems specifically the discontinuous, no differentiable, stochastic or highly nonlinear objective function [28-31].

The present study describes the efficiency of $\mathrm{Fe}_{2} \mathrm{O}_{3}$-NPs-AC as solid phase (adsorbent) for extraction of SO from wastewater samples. The effects of various parameters including $\mathrm{pH}$, amount of adsorbent, ultrasound time and eluent volume were investigated RSM and ANN-GA. The aims of this study are: (i) to obtain a predictive model based on RSM and ANN-GA techniques for prediction of the extraction percentage of SO dye, (ii) to maximize the 
extraction percentage of SO dye using RSM and ANN-GA models, (iii) to develop a simple and fast method for extraction of SO dye.

\section{Experimental}

\subsection{Chemicals and instruments}

Ultrapure water (obtained by Milli-Q system, Bedford, MA, USA) was used in all experiments. Stock standard solution of safranin $\mathrm{O}(\mathrm{SO})$ dye with a concentration of $100 \mathrm{mg} \mathrm{L}^{-1}$ were obtained by dissolving appropriate amounts of SO dye (Merck, Darmstadt, Germany). Working standard solutions were obtained by appropriate dilution of the stock standard solutions. THF, methanol, ethanol, acetone, acetonitrile, and DMF, which were used as eluent solvents, were from Merck (Merck, Darmstadt, Germany) were used. X- ray diffraction (XRD, Philips PW 1800) was performed to characterize the phase and structure of the prepared $\mathrm{Fe}_{2} \mathrm{O}_{3}-\mathrm{NPs}-\mathrm{AC}$ using $\mathrm{Cu}_{\mathrm{ka}}$ radiation (40 KV and $40 \mathrm{~mA}$ ) at angles ranging from 10 to $80^{\circ}$. The morphology of the $\mathrm{Fe}_{2} \mathrm{O}_{3}$-NPs-AC were observed by scanning electron microscopy (SEM: Hitachi S- 4160) under an acceleration voltage of $26 \mathrm{KV}$. The absorbance was measured by a UV-vis spectrophotometer (model V-530, Jasco, Japan) at $520 \mathrm{~nm}$ using quartz micro cells. A Hermle Labortechnik GmbH centrifuge model Z206A (Germany) was used to accelerate the phase separation. A Metrohm digital $\mathrm{pH}$-meter model 686 (Switzerland, Swiss) with a combined $\mathrm{Ag} / \mathrm{AgCl}$ glass electrode was used for $\mathrm{pH}$ adjustments. An ultrasonic bath with heating system (Tecno-GAZ SPA Ultrasonic System) at $40 \mathrm{kHz}$ of frequency and $130 \mathrm{~W}$ of power was used for the ultrasound assisted adsorption procedure. The STATISTICA and DesignExpert software (Stat Soft Inc., Tulsa, USA) was used for experimental design analysis and their subsequent regression analysis.

\subsection{Ultrasound assisted dispersive solid phase microextraction method}

$10 \mathrm{~mL}$ solutions consisting of $500 \mathrm{ng} \mathrm{mL}^{-1}$ concentration of $\mathrm{SO}$ dye at $\mathrm{pH} 6.5$ was mixed with $1.1 \mathrm{mg}$ adsorbent in test tube by $15 \mathrm{~mL}$ and the test tube was entered in ultrasound system for $8 \mathrm{~min}$. Subsequently, the enriched SO dye was eluted by $150 \mu \mathrm{L}$ of DMF as eluent solvent. In this step, SO were extracted into fine droplets of DMF. After 8 min sonication, the test tube was placed on the vertex for $4 \mathrm{~min}$ and then the mixture solution was centrifuged for 5 min at $3500 \mathrm{rpm}$. The eluent solvent was separated using a syringe. Then $50 \mu \mathrm{L}$ of eluent solvent consisting SO entered in quartz microcells and determination of extraction percentage by spectrophotometric method. To develop 
the USA-DSPME-UV procedure for enrichment of SO, some parameters controlling extraction ( $\mathrm{pH}$, amount of adsorbent, ultrasound time and eluent volume) were investigated by RSM and ANN-GA. Additionally, under optimum condition obtained from ANN-GA calculated quantitative parameters. Extraction recovery (ER \%) and enrichment factor $(\mathrm{EF})$ of SO were calculated as follows [22, 23]:

$$
\begin{aligned}
& \mathrm{ER} \%=\frac{\mathrm{C}_{\text {org }} \mathrm{V}_{\text {org }}}{\mathrm{C}_{\text {initial }} \mathrm{V}_{\mathrm{aq}}} \times 100 \\
& \mathrm{EF}=\frac{\mathrm{C}_{\text {Sed }}}{\mathrm{C}_{0}}
\end{aligned}
$$

where $\mathrm{C}$ and $\mathrm{V}$ are the concentration and volume, and the suffixes org and initial indicate eluent and initial solution, respectively. The relative recoveries $(\mathrm{RR} \%)$ of the analytes were used as the parameters to evaluate the method efficiency. The RR\% was calculated by eq. (3).

$$
\mathrm{RR} \%=\left(\frac{\mathrm{C}_{\text {found }} \mathrm{C}_{\text {real }}}{\mathrm{C}_{\text {added }}}\right) \times 100
$$

The $\mathrm{C}_{\text {found }}, \mathrm{C}_{\text {real }}$, and $\mathrm{C}_{\mathrm{added}}$ are defined as the concentration of analyte after addition of a known amount of standard in the real sample, the concentration of analyte in the real sample and the concentration of known amount of standard which was spiked to the real sample, respectively [32].

\subsection{Preparation $\mathrm{Fe}_{2} \mathrm{O}_{3}-\mathrm{NPs}-\mathrm{AC}$}

The $\mathrm{Fe}_{2} \mathrm{O}_{3}$-NPs-AC were synthesized via an in situ crystallization technique. Briefly, $1.5 \mathrm{~g}$ active carbon (AC) were added to $20 \mathrm{~mL}$ of distilled water and then transferred to an ultrasonic bath to obtain a uniform suspension for 20 min. Then $1.52 \mathrm{~g} \mathrm{Fe}\left(\mathrm{NO}_{3}\right)_{3} \cdot 6 \mathrm{H}_{2} \mathrm{O}$ was added and sonication was contention used for $10 \mathrm{~min}$. After that, $1 \mathrm{~g} \mathrm{NaOH}$ was directly added to the $\mathrm{Fe}(\mathrm{OH})_{3}$ and $\mathrm{AC}$ suspension under fierce stirring for $30 \mathrm{~min}$. Then, the resultant system 
was transferred into a stainless steel autoclave and held at $160{ }^{\circ} \mathrm{C}$ for $22 \mathrm{~h}$. After cooling to room temperature naturally, the as-prepared products were filtered, washed with distilled water, and dried at $80{ }^{\circ} \mathrm{C}$ for $12 \mathrm{~h}$.

\subsection{Experimental design and statistical analysis}

Response Surface Methodology (RSM) is a technique for optimization and analyzing the relationship between independent variables and response (ER \%), both as linear or nonlinear forms to determine an optimum response. Central Composite Design (CCD) in RSM is the most popular class of design used for fitting a second order model, especially in the extraction process [33]. In this study, four important factors were considered in experiments with five levels. Table 1 shows the ranges and levels of the four independent variables with actual and coded values of each parameter. The independent variables are coded to two levels namely: low $(-1)$ and high $(+1)$, whereas the axial points are coded as -2 and +2 . A five-level-four-factor central composite design was employed to fit a second-order response surface model which required 31 experiments, including 16 factorial, 8 axial points and 7 replicates at the center points, which are used to determine the experimental error (pure error) and the reproducibility of the data. 31 experiments were conducted in random order and the extraction percentage was calculated. The complete CCD design matrix in terms of real independent variable is presented and the corresponding results are given in Table 2. The experiments were run in replicates to minimize errors. The linear and quadratic model with interactions can be seen in the following equation [10]:

$y=\beta_{0}+\sum_{i=1}^{k} \beta_{i} x_{i}+\sum_{i=1}^{k} \beta_{i i} x_{i}^{2}+\sum_{i=1}^{k} \sum_{j=1}^{k} \beta_{i j} x_{i} x_{j}+\varepsilon$

where $y$ expresses response (extraction percentage), $x_{i}$ and $x_{j}$ represent independent variables, $\beta_{0}$ indicates the intercept constant, $\beta_{\mathrm{i}}$ show the coefficients of linear terms, $\beta_{\mathrm{ii}}$ represent the coefficients of quadratic terms, $\beta_{\mathrm{ij}}$ show the coefficients of interaction terms, $\varepsilon$ indicates experimental error and $\mathrm{k}$ represents the number of independent variables. The data were analyzed using STATISTICA and Design-Expert software and the coefficients were

interpreted using F-test. Analysis of variance (ANOVA), regression analysis and plotting of 3D plot were used to establish the optimum conditions for the extraction percentage. The accuracy and general ability of the polynomial model could be evaluated by the coefficient of determination $\mathrm{R}^{2}$. The experiment was carried out in triplicates [34]. 


\subsection{Artificial neural network (ANN)}

An artificial neural network (ANN) is a simplified computational and mathematical model that is inspired by the structure of biological neural networks. In this approach weighted sum of inputs arriving at each neuron is passed through an activation function (generally nonlinear) to generate an output signal [35]. Artificial neural network has been used successfully for modelling of dye extraction. MATLAB (The Math works, Inc., Ver. 7.0.1) was chosen to develop the ANN model using neural network toolbox from the data. In this present study, a three-layer feed forward back propagation neural network with a linear transfer function was developed for modeling of SO extraction by $\mathrm{Fe}_{2} \mathrm{O}_{3}$-NPs-AC. ANN has three layers: an input layer represents as independent variables; the output layer gives the dependent variables and one or more intermediate nodes act as a collection of feature detectors. As we have chosen $\mathrm{pH}$, amount of adsorbent, ultrasound time and eluent volume as independent variables, and extraction percentage of $\mathrm{SO}$ as dependent variables, network model with four neurons in the input layer and one in the output layer was the obvious choice. The number of hidden nodes determines the model complexity of a neural network. However, too many neurons in the hidden layer may also result in the over fitting of the model data. After a number of training trials, the best neural network model was generated. The maximum number of epochs (training cycles) was chosen by a trial and error approach [36].

\subsection{Genetic Algorithm (GA)}

GA is an adaptive search procedure based on the mechanics of natural genetics and natural selection and has been used for a variety of search problems. GA starts by generating a random population. Each individual of the population represents a possible solution and is coded by binary string (called' 'chromosome e") [37]. The bit value " 1 " represents a select variable; the bit value " 0 " represents an unselect variable. The "fitness", which is measure of adaptation to environment, is calculated for each individual. After the evaluation of all the individuals, the next population is obtained busing genetic operations. As the algorithm proceeds, the individual's of the population are gradually improved [38]. In the proposed method, after developing the central composite design and trained ANN, the genetic algorithm can be used to optimize the input variables, with an objective to maximize the percentage of SO dye extraction. GA based optimization processes were executed by using central composite design and trained ANN models as the fitness functions to give the global optimized solutions. 


\section{Results and discussion}

\subsection{Characterization of adsorbent}

The microstructure and morphology of the $\mathrm{Fe}_{2} \mathrm{O}_{3}$-NPs and $\mathrm{Fe}_{2} \mathrm{O}_{3}$-NPs -AC (Fig. 1a, b) shows the $\mathrm{Fe}_{2} \mathrm{O}_{3}$ nanoparticles were well decorated on the activated carbon. These results clearly indicate the presence of strong interaction between $\mathrm{AC}$ and $\mathrm{Fe}_{2} \mathrm{O}_{3}$ nanoparticles. The highly dispersed metal oxide nanoparticles on high surface area of AC may create a better communication between the adsorbent and analyte.

Transmission electron microscopy (TEM) was employed to analyze detailed the crystal structure of $\mathrm{Fe}_{2} \mathrm{O}_{3}-\mathrm{NPs}_{\text {(Fig. }}$. 2a) present the high magnification TEM images of $\mathrm{Fe}_{2} \mathrm{O}_{3}$-NPs, where the uniform distribution of particles is observed with the particle size of $10-25 \mathrm{~nm}$.

The crystalline nature of the $\mathrm{Fe}_{2} \mathrm{O}_{3}$-NPs-AC was investigated by powder XRD (Fig. 2b) shows the presence of welldefined peaks that are centered at ca. $23.9^{\circ}(012), 33^{\circ}(104), 35.4^{\circ}(110), 40.7^{\circ}(113), 49.3^{\circ}(024), 53.9^{\circ}(116), 57.4^{\circ}$ $(018), 62.3^{\circ}(214), 63.9^{\circ}(300), 69.5^{\circ}(208), 72.7^{\circ}(119)$ and $76.3^{\circ}(220)$, where all the diffraction peaks were well indexed to the rhombohedra crystal structure of $\mathrm{Fe}_{2} \mathrm{O}_{3}$ (JCPDS No. 33-0664). All the peaks observed in the composites are related to the $\mathrm{Fe}_{2} \mathrm{O}_{3}$ nanoparticles. The crystallite size was estimated from the width of (110) plane according to the Scherer's formula $\mathrm{D}=\mathrm{k} \lambda / \beta \operatorname{Cos} \theta$, where constant $\mathrm{k}$ is $0.9-1, \beta$ is the full width half maxima and $\theta$ is the Bragg angle. The size was found to be $17.5 \mathrm{~nm}$.

\subsection{Optimization of eluent solvent}

Preparatory experiments were done to choose the best eluent solvent. Therefore, USA-NSPME method was applied for extraction of $500 \mathrm{ng} \mathrm{mL}^{-1}$ of $\mathrm{SO}$ from $10.0 \mathrm{~mL}$ aqueous solution. In this stage, desorption of $\mathrm{SO}$ dye from $\mathrm{Fe}_{2} \mathrm{O}_{3^{-}}$ NPs-AC was studied by means of $200.0 \mu \mathrm{L}$ of different organic solvents (acetonitrile, acetone, methanol, THF, ethanol and DMF. After desorption process, $100.0 \mu \mathrm{L}$ of organic phase transmission to micro cell for subsequent analysis. It was found that among the five used solvents, the maximum extraction $\mathrm{r}$ percentage was obtained using DMF as desorption solvents for eluting adsorb $\mathrm{SO}$ dye from $\mathrm{Fe}_{2} \mathrm{O}_{3}$-NPs-AC. Therefore, DMF was chosen for subsequent experiments and the effect of type of eluent on the extraction percentage of SO dye were shown in Fig. 3. The effect of the volume of desorption solution on desorption efficiency of the SO dye was also investigated by subsequent experimental design. 


\subsection{Central composite design (CCD)}

In the first step of the study, the effects of operating variables such as initial $\mathrm{pH}$, amount of adsorbent, sonication time and eluent volume on extraction of SO were investigated using RSM according to CCD. In the second step, the main objective was to achieve optimal condition for determination of SO dye in wastewater. The batch runs were conducted in CCD designed experiments to visualize the effects of independent factors on extraction of SO and the results along with the experimental conditions. The experimental results were evaluated and the approximating function of extraction of SO was obtained in eq. (5) by utilizing STATISTICA 10. The least squares method was used to estimate the parameters in the approximating polynomial, and then the response surface analysis was done in terms of the fitted surface. The analysis of the fitted surface is approximately equivalent to analysis of the actual system if the fitted surface is an adequate approximation of the true response function. In most cases, the secondorder model is adequate. Eq. (5) could be used in predicting the response for the given values of initial $\mathrm{pH}$, amount of adsorbent, ultrasound time and eluent volume.

$\mathrm{ER} \% \mathrm{SO}=-61.80+43.57 \mathrm{~A}-5.93 \mathrm{~B}+5.02 \mathrm{C}+0.02 \mathrm{D}+1.46 \mathrm{AB}+0.70 \mathrm{AC}+$

$0.10 \mathrm{AD}-0.60 \mathrm{BC}+0.06 \mathrm{BD}-0.02 \mathrm{CD}-5.10 \mathrm{~A}^{2}-5.10 \mathrm{~B}^{2}-0.24 \mathrm{C}^{2}-0.02 \mathrm{D}^{2}$

In eq. (5), $\mathrm{y}$ is the extraction recovery of SO dye. A, B, C and D are corresponding to independent variables of initial $\mathrm{pH}$, amount of adsorbent, ultrasound time and eluent volume, respectively. The negative coefficients for the model components $\mathrm{B}, \mathrm{BC}, \mathrm{CD}, \mathrm{A}^{2}, \mathrm{~B}^{2}, \mathrm{C}^{2}$ and $\mathrm{D}^{2}$ indicate the unfavorable effects on the extraction recovery of SO dye. While, the positive coefficients for $\mathrm{A}, \mathrm{C}, \mathrm{D}, \mathrm{AC}$ and $\mathrm{BD}$ indicate favorable effects on the extraction recovery of SO dye. The significance of each model parameter will be determined by the statistical analysis.

ANOVA results of this quadratic model presented in Table 3 indicating that it could be used to navigate the design space. The appropriate procedure for testing the equality of several means is the analysis of variance (ANOVA) which has a much wider application. The goodness of fit of regression equation developed could be measured by adjusted determination coefficient. The $\mathrm{R}^{2}$ value of 0.9929 (Fig. 4a) and adjusted $\mathrm{R}^{2}$ of 0.9867 shows that the model could be significant predicting the response and explaining $95 \%$ of the variability in the extraction of SO dye. The Predicted $R^{2}$ of 0.9642 is in reasonable agreement with the "Adjusted $R^{2}$ of 0.9867 . The statistical significance of the equation was evaluated by F-test and ANOVA (analysis of variance) which showed that the model was statistically significant at 95\% confidence level $(\mathrm{p}<0.0001)$. ANOVA reported the model F-value of 160.4 implying that the model is significant. P-value denotes the importance of each coefficient, helping in understanding 
the interactions among the variables. The model also depicted the statistically non significant lack of fit $(\mathrm{p}>0.05)$, indicating that the responses are adequate for employing in this model [39].

Fig. $4 \mathrm{~b}$ shows the residual plot versus run orders. The random pattern of residuals would indicate the model adequacy. Additionally, assuming that the data have a normal distribution is necessary to integral analysis of the experimental data [40]. Therefore, the normal probability plot of residual values is shown in Fig. 4c. Evidently, the figure demonstrates that the experimental data fall close enough to the straight line suggesting normal distribution of the data [41]. To test the normality assumption, Box-Cox normality plot was assessed and the lowest point on the plot represented the best value of lambda (1.01) that suggested no need for transformation of extraction yield response (Fig. 4d). Adequate precision measures the signal to noise ratio and a ratio greater than 4 is desirable. Therefore, in the quadratic model of extraction of SO, the ratio of 54.01 indicate an adequate signal for the model to be used to navigate the design space [42].

\subsection{Response surface plot}

Response surface plot was used to determine extraction of SO dye over interactive variables adsorbent and ultrasound time, and $\mathrm{pH}$ and eluent volume (Fig. 5). Fig. 5a shows the effect of adsorbent dosage and ultrasound time on the extraction of SO. Adsorbent dosage and ultrasound time are the most important parameters influencing on the extraction of SO. As can be seen from Fig. 5a, the maximum extraction percentage of SO dye was obtained at about $1.5 \mathrm{mg}$ of adsorbent and ultrasound time $8 \mathrm{~min}$. The extraction percentage of SO dye increases with decreasing adsorbent up to $1.5 \mathrm{mg}$ and afterward shows a slight decrease. The effect of $\mathrm{pH}$ and eluent volume on extraction of $\mathrm{SO}$ is shown in Fig. 5b as a 3D response surface plot. The extraction of SO increased with the decrease in eluent volume. Also the extraction of SO dye increased up to $\mathrm{pH} 7.0$ and above this value decreased with the increase $\mathrm{pH}$.

\subsection{Optimization process}

The profile for predicted values and desirability option in the STATISTICA and Design-Expert software is used for the optimization process. The scale in the range of 0.0 (undesirable) to 1.0 (very desirable) must be maximized following best and efficient selection of variables. The CCD design matrix results (Table 2) show the maximum (95.95\%) and minimum (59.61\%) extraction of SO dye. According to these values, DF settings for each dependent 
variable of extraction percentage are depicted on the right hand side of Fig. 6: desirability of 1.0 was assigned for maximum extraction (95.95\%), 0.0 for minimum (59.61\%) and 0.5 for middle (77.78\%). The left hand side of Fig. 6 (bottom) shows the application of individual desirability scores calculation of the extraction percentage. Since desirability 1.0 was selected as the target value, the overall response obtained from these plots with the current level of each variable in the model is depicted at the top (left) of Fig. 6. The CCD optimization design matrix (Fig. 6) show that maximum extraction percentage of SO (96.12\% and desirability of 1.0) was achieved at following conditions: $1.5 \mathrm{mg}$ of adsorbent, ultrasound time $8 \mathrm{~min}$, eluent volume $180 \mu \mathrm{L}$ and $\mathrm{pH}$ 7.0.

\subsection{Modeling and optimization by ANN-GA}

ANN has been successfully utilized for prediction extraction processes of different analyte from aqueous solution. In the present work, a feed-forward back propagation network with tangent sigmoid transfer function (tansig) at hidden layer and a linear transfer function (purelin) at output layer was successfully applied. During the net training process, the mean square error (MSE) that was chosen as the function of error performance has minimum value at 9 neurons among examined neurons from 1 to 15 . Network training performed in 9 epochs [43].

The relationship between the input and output data was achieved by ANN to approximate any function with finite number of discontinuities by learning their relationships. The criterion for selection of the optimum ANN structure is the MSE of the test data as well as the correlation coefficient $\left(\mathrm{R}^{2}\right)$. The smallest MSE was considered for train function, while the result of Table 4 shows the relation between the number of neurons, $R^{2}$ and MSE for presented ANN. It was found that using 9 hidden neurons, the $\mathrm{R}^{2}$ and MSE reached values of 0.9993 and 0.09964 , respectively. Also ANN offered the weights that are coefficients between the artificial neurons and are considered analogous to synapse strengths between the axons and dendrites in real biological neurons. Table 5 shows the provided weights by ANN in the present study. The intensity of influence of each input variable on the output variable was calculated using the neural weight data.

Fig. 7a shows the MSE versus the number of epochs for optimal ANN models show that the training was stopped after 9. The good simulation and correlation of experimental and predicted results (test data) for the optimum number of hidden layer neurons, which confirm accuracy of the neural network for modeling and prediction of the outlet composition of extraction percentage, while, Fig. 7b Show the plot of Error Histogram for extraction 
percentage of $\mathrm{SO}$ dye by $\mathrm{Fe}_{2} \mathrm{O}_{3}$-NPs-AC and also this plot indicates that the errors in this extraction process is very low.

In recent years, combination ANN-GA has been successfully applied for the optimization of various systems. In this study, GA used by equations that achieved from ANN models. The method starts with a population of random regimes using $\mathrm{pH}$, adsorbent mass $(\mathrm{mg})$, ultrasound time $(\mathrm{min})$ and eluent volume $(\mu \mathrm{L})$ as the optimization parameters. The objective function was that equation achieved from ANN model that correlates the inputs with output and can be defined as follows [37]:

$y=-\operatorname{purelin}\left(w_{2} * \operatorname{tansig}\left(w_{1} *[x(1) ; x(2) ; x(3) ; x(4)]+b_{1}\right)+b_{2}\right)$

where, $\mathrm{x}(1), \mathrm{x}(2), \mathrm{x}(3)$ and $\mathrm{x}(4)$ represent the inputs, w1 and b1 are the weight and bias of hidden layer and w2 and b2 are the weight and bias of output layers. Table 5 shows the weight and bias values of each layer, which achieved from the best ANN model. The Matlab R2013a genetic algorithm toolbox has been applied for GA processes with 51 generation (Fig. 8a), population size of 20 with scattered crossover function of 0.8 , Rank scaling function and Stochastic uniform option. For extraction percentage of SO dye the ANN-GA method predicts maximum extraction percentage (99.92\%) at pH 6.5, $1.1 \mathrm{mg}$ of adsorbent, ultrasound time $10 \mathrm{~min}$ and $150 \mu \mathrm{L}$ of eluent volume (Fig. 8b).

\subsection{Comparison of CCD and ANN-GA}

The CCD and ANN-GA are techniques capable to solve linear and non-linear multivariate problems. Both models were used for optimization of extraction of $\mathrm{SO}$ dye by $\mathrm{Fe}_{2} \mathrm{O}_{3}$-NPs-AC. In addition, both models were well fitted to experimental response. The CCD approach has a regression equation for forecasting and achieving optimum conditions of variables unlike ANN-GA. However, the major limitation of CCD is the capability to solve only quadratic non-linear correlation. Besides, the ANN-GA model is able to solve any form of non-linearity. Therefore, the advantage of GA can overcome that of CCD. The predicted optimum conditions resulted from CCD and ANNGA presented in Table 6. The experimental results showed an average SO dye extraction efficiency of $99.74 \pm$ $1.81 \%(\mathrm{n}=5)$. The existence of the high degree of agreement between the experimental results and predicted optimum results indicating that the ANN-GA could be used effectively for the evaluation and optimization of the effects of the extraction independent variables on the extraction efficiency of SO dye from wastewater. 


\subsection{Method validation}

After optimization, the results showed that the USA-DSPME-UV has the higher extraction efficiency (in terms of enrichment factor) for the SO dye in the samples. Under the optimum conditions obtained from ANN-GA, limits of detection (LOD), limits of quantification (LOQ), linear dynamic ranges (LDR), and relative standard deviations (in terms of repeatability) of USA-DSPME-UV method were calculated (Table 7). Based on the calibration curves, sensitivity of the method was evaluated in terms of LOD and LOQ, which were statistically calculated as 3 and 10 times of the standard deviations of five replicate extractions of SO dye minimum detectable concentrations divided on the calibration slope. Repeatability (intra-day and inter-day precisions) were evaluated by analyzing five replicates of the model sample in the same day and five different days. The enrichment factors was calculated based on eq. (2). Five replicate extractions were performed in all calculations.

\subsection{Study of selectivity}

To evaluate the selectivity of the developed system, the effect of typically potential interfering ions and dyes were investigated and the results are shown in Table 8. According to the data, some major matrix ions present in natural water samples have no obvious interferences, while some other heavy metal ions have less tolerable limits due to the competition and co-extraction effect. These ions had no interference with the USA-DSPME-UV method under the optimum conditions due to probably low stabilities of their SO dye. These metal ions and dyes did not show any interfering effect at their studied levels for the extraction of SO dye in some various aqueous samples.

\subsection{Analysis of real samples and validity of the method}

Water is one of the important pathways of pollutants entering human bodies. Considering the biological and environmental significance of SO dyes, several real water and wastewater samples and certified reference water and industry wastewater samples were analyzed to validate the accuracy and applicability of the established method. The analytical results were summarized in Table 9. The results of certified reference samples were in good agreement with the certified values. For real water and wastewater samples, the extraction percentage for the spiked samples were in the acceptable range of $93.27-99.41 \%$. 


\section{Conclusion}

In this study, The $\mathrm{Fe}_{2} \mathrm{O}_{3}$-NPs-AC was successfully synthesized and it was characterized by XRD, FE-SEM and TEM methods, then used to extraction of SO dye in USA-DSPME-UV method. Afterwards, the significant variables were optimized using RSM and ANN-GA. Under the optimum conditions, the enrichment factors was 124.59 . The linear range was $25-3500 \mathrm{ng} \mathrm{mL}^{-1}$ and LODs was $6.3 \mathrm{ng} \mathrm{mL}^{-1}$. The relative standard deviations (RSDs) were in the range of $2.8 \%$. The relative recoveries of SO dye from different water and wastewater samples were $93.27-99.41 \%$. The resulting Optimized procedure allowed for the quantification of ultra-trace levels of SO dye in water and wastewater samples using USA-DSPME-UV coupled to spectrophotometry method. The main benefits of the proposed methodology for extraction and determination of SO dye were low sample consumption, minimum use of toxic organic solvent, rejection of matrix constituent, simplicity and high enrichment factor.

\section{Acknowledgement}

The authors grateful from the Iranian National Sciences Foundation and Research Council of the University of Yasouj for their financial support.

\section{References}

[1] J. Luan, P.-X. Hou, C. Liu, C. Shi, G.-X. Li, H.-M. Cheng, Efficient adsorption of organic dyes on a flexible single-wall carbon nanotube film, J. Mater. Chem. A, 4 (2016) 1191-1194.

[2] A. Asfaram, M. Ghaedi, S. Hajati, M. Rezaeinejad, A. Goudarzi, M.K. Purkait, Rapid removal of Auramine-O and Methylene blue by $\mathrm{ZnS}: \mathrm{Cu}$ nanoparticles loaded on activated carbon: A response surface methodology approach, J. Taiwan Inst. Chem. Eng., 53 (2015) 80-91.

[3] H. Yan, J. Qiao, H. Wang, G. Yang, K.H. Row, Molecularly imprinted solid-phase extraction combined with ultrasound-assisted dispersive liquid-liquid microextraction for the determination of four Sudan dyes in sausage samples, The Analyst, 136 (2011) 2629-2634.

[4] M. Ghaedi, S. Khodadoust, H. Sadeghi, M.A. Khodadoust, R. Armand, A. Fatehi, Application of ultrasonic radiation for simultaneous removal of auramine $\mathrm{O}$ and safranine $\mathrm{O}$ by copper sulfide nanoparticles: Experimental design, Spectrochim. Acta Part A, 136, Part B (2015) 1069-1075.

[5] M.K. Sahu, U.K. Sahu, R.K. Patel, Adsorption of safranin-O dye on $\mathrm{CO}_{2}$ neutralized activated red mud waste: process modelling, analysis and optimization using statistical design, RSC Adv., 5 (2015) 42294-42304.

[6] M. Bouraada, M. Lafjah, M.S. Ouali, L.C. de Menorval, Basic dye removal from aqueous solutions by dodecylsulfate- and dodecyl benzene sulfonate-intercalated hydrotalcite, J. Hazard. Mater., 153 (2008) 911-918.

[7] Q. Liu, B. Yang, L. Zhang, R. Huang, Adsorption of an anionic azo dye by cross-linked chitosan/bentonite composite, Int. J. Biolog. Macromol., 72 (2015) 1129-1135.

[8] J.Z. Yi, L.M. Zhang, Removal of methylene blue dye from aqueous solution by adsorption onto sodium humate/polyacrylamide/clay hybrid hydrogels, Bioresour. Technol., 99 (2008) 2182-2186. 
[9] U. Tezcan Un, F. Ates, N. Erginel, O. Ozcan, E. Oduncu, Adsorption of Disperse Orange 30 dye onto activated carbon derived from Holm Oak (Quercus Ilex) acorns: A 3(k) factorial design and analysis, J. Environ. Manag., 155 (2015) 89-96.

[10] A. Asfaram, M. Ghaedi, A. Goudarzi, M. Rajabi, Response surface methodology approach for optimization of

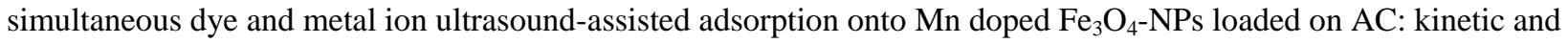
isothermal studies, Dalton Trans., 44 (2015) 14707-14723.

[11] M. Roosta, M. Ghaedi, A. Asfaram, Simultaneous ultrasonic-assisted removal of malachite green and safranin O by copper nanowires loaded on activated carbon: central composite design optimization, RSC Adv., 5 (2015) 57021-57029.

[12] A. Asfaram, M. Ghaedi, A. Goudarzi, Optimization of ultrasound-assisted dispersive solid-phase microextraction based on nanoparticles followed by spectrophotometry for the simultaneous determination of dyes using experimental design, Ultrason. Sonochem., 32 (2016) 407-417.

[13] A. Asfaram, M. Ghaedi, S. Hajati, A. Goudarzi, Synthesis of magnetic $\gamma-\mathrm{Fe}_{2} \mathrm{O}_{3}$-based nanomaterial for ultrasonic assisted dyes adsorption: Modeling and optimization, Ultrason. Sonochem., 32 (2016) 418-431.

[14] F.N. Azad, M. Ghaedi, K. Dashtian, S. Hajati, V. Pezeshkpour, Ultrasonically assisted hydrothermal synthesis of activated carbon-HKUST-1-MOF hybrid for efficient simultaneous ultrasound-assisted removal of ternary organic dyes and antibacterial investigation: Taguchi optimization, Ultrason. Sonochem., 31 (2016) $383-393$.

[15] A. Asfaram, M. Ghaedi, S. Hajati, A. Goudarzi, A.A. Bazrafshan, Simultaneous ultrasound-assisted ternary adsorption of dyes onto copper-doped zinc sulfide nanoparticles loaded on activated carbon: optimization by response surface methodology, Spectrochim. acta. Part A, 145 (2015) 203-212.

[16] S. Dashamiri, M. Ghaedi, K. Dashtian, M.R. Rahimi, A. Goudarzi, R. Jannesar, Ultrasonic enhancement of the simultaneous removal of quaternary toxic organic dyes by $\mathrm{CuO}$ nanoparticles loaded on activated carbon: Central composite design, kinetic and isotherm study, Ultrason. Sonochem., 31 (2016) 546-557.

[17] V. Sivakumar, J.L. Anna, J. Vijayeeswarri, G. Swaminathan, Ultrasound assisted enhancement in natural dye extraction from beetroot for industrial applications and natural dyeing of leather, Ultrason. Sonochem., 16 (2009) 782-789.

[18] G. Fang, G. Li, C. Pang, W. Li, D. Wang, C. Liu, Ultrasound-Assisted Extraction of Pristimerin from Celastrus orbiculatus Using Response Surface Methodology, Biol. Pharm. Bull., 39 (2016) 97-103.

[19] Y.E. Unsal, M. Soylak, M. Tuzen, Ultrasound-assisted ionic liquid-based dispersive liquid-liquid microextraction for preconcentration of patent blue $\mathrm{V}$ and its determination in food samples by UV-visible spectrophotometry, Environ. Monit. Assess., 187 (2015) 203.

[20] M. Roosta, M. Ghaedi, A. Daneshfar, R. Sahraei, Ultrasound assisted microextraction-nano material solid phase dispersion for extraction and determination of thymol and carvacrol in pharmaceutical samples: Experimental design methodology, J. Chromatogr. B, 975 (2015) 34-39.

[21] M. Manoochehri, A.A. Asgharinezhad, M. Safaei, Determination of Aflatoxin M1 in Milk Powder by Ultrasonic-Assisted Extraction and Dispersive Solid-Phase Clean-up, J. Chromatogr. Sci., 53 (2015) 1000-1006.

[22] A. Asfaram, M. Ghaedi, A. Goudarzi, M. Soylak, Comparison between dispersive liquid-liquid microextraction and ultrasound-assisted nanoparticles-dispersive solid-phase microextraction combined with microvolume spectrophotometry method for the determination of Auramine-O in water samples, RSC Adv., 5 (2015) 3908439096. 
[23] A. Asfaram, M. Ghaedi, A. Goudarzi, M. Soylak, S. Mehdizadeh Langroodi, Magnetic nanoparticle based dispersive micro-solid-phase extraction for the determination of malachite green in water samples: optimized experimental design, New J. Chem., 39 (2015) 9813-9823.

[24] Y. Zhang, J. Xu, Z. Yuan, H. Xu, Q. Yu, Artificial neural network-genetic algorithm based optimization for the immobilization of cellulase on the smart polymer Eudragit L-100, Bioresour. Technol., 101 (2010) 3153-3158.

[25] M. Ghaedi, A. Daneshfar, A. Ahmadi, M.S. Momeni, Artificial neural network-genetic algorithm based optimization for the adsorption of phenol red (PR) onto gold and titanium dioxide nanoparticles loaded on activated carbon, J. Ind. Eng. Chem., 21 (2015) 587-598.

[26] A.A. Bazrafshan, S. Hajati, M. Ghaedi, Synthesis of regenerable $\mathrm{Zn}(\mathrm{OH})_{2}$ nanoparticle-loaded activated carbon for the ultrasound-assisted removal of malachite green: optimization, isotherm and kinetics, RSC Adv., 5 (2015) 79119-79128.

[27] A. Asfaram, M. Ghaedi, S. Agarwal, I. Tyagi, V. Kumar Gupta, Removal of basic dye Auramine-O by ZnS:Cu nanoparticles loaded on activated carbon: optimization of parameters using response surface methodology with central composite design, RSC Adv., 5 (2015) 18438-18450.

[28] M. Ghaedi, A. Ansari, F. Bahari, A.M. Ghaedi, A. Vafaei, A hybrid artificial neural network and particle swarm optimization for prediction of removal of hazardous dye brilliant green from aqueous solution using zinc sulfide nanoparticle loaded on activated carbon, Spectrochim. Acta Part A, 137 (2015) 1004-1015.

[29] M. Ghaedi, S. Hajati, M. Zare, M. Zare, S.Y. Shajaripour Jaberi, Experimental design for simultaneous analysis of malachite green and methylene blue; derivative spectrophotometry and principal component-artificial neural network, RSC Adv., 5 (2015) 38939-38947.

[30] M. Ghaedi, A. Ansari, P. Assefi Nejad, A. Ghaedi, A. Vafaei, M.H. Habibi, Artificial neural network and Bees Algorithm for removal of Eosin B using Cobalt Oxide Nanoparticle-activated carbon: Isotherm and Kinetics study, Environ. Prog. Sust. Energy, 34 (2015) 155-168.

[31] J. Pazourek, D. Gajdosova, M. Spanila, M. Farkova, K. Novotna, J. Havel, Analysis of polyphenols in wines: correlation between total polyphenolic content and antioxidant potential from photometric measurements. Prediction of cultivars and vintage from capillary zone electrophoresis fingerprints using artificial neural network, J. Chromatogr. A, 1081 (2005) 48-54.

[32] E. Alipanahpour Dil, M. Ghaedi, A. Asfaram, A. Goudarzi, Synthesis and characterization of ZnO-nanorods loaded onto activated carbon and its application for efficient solid phase extraction and determination of BG from water samples by micro-volume spectrophotometry, New J. Chem., 39 (2015) 9407-9414.

[33] E.A. Dil, M. Ghaedi, A. Ghaedi, A. Asfaram, M. Jamshidi, M.K. Purkait, Application of artificial neural network and response surface methodology for the removal of crystal violet by zinc oxide nanorods loaded on activate carbon: kinetics and equilibrium study, J. Taiwan Inst. Chem. Eng., 59 (2016) 210-220.

[34] M. Ghaedi, H.Z. Khafri, A. Asfaram, A. Goudarzi, Response surface methodology approach for optimization of adsorption of Janus Green B from aqueous solution onto $\mathrm{ZnO} / \mathrm{Zn}(\mathrm{OH})_{2}-\mathrm{NP}-\mathrm{AC}$ : Kinetic and isotherm study, Spectrochim. Acta Part A, 152 (2016) 233-240.

[35] E.A. Dil, M. Ghaedi, A.M. Ghaedi, A. Asfaram, A. Goudarzi, S. Hajati, M. Soylak, S. Agarwal, V.K. Gupta, Modeling of quaternary dyes adsorption onto $\mathrm{ZnO}-\mathrm{NR}-\mathrm{AC}$ artificial neural network: Analysis by derivative spectrophotometry, J. Ind. Eng. Chem., 34 (2016) 186-197.

[36] P. Banerjee, S. Sau, P. Das, A. Mukhopadhayay, Optimization and modelling of synthetic azo dye wastewater treatment using Graphene oxide nanoplatelets: Characterization toxicity evaluation and optimization using Artificial Neural Network, Ecotoxicol. Environ. Saf., 119 (2015) 47-57. 
[37] M. Khajeh, Z.S. Moghaddam, M. Bohlooli, A. Khajeh, Modeling of Dispersive Liquid-Liquid Microextraction for Determination of Essential Oil from Borago officinalis L. By Using Combination of Artificial Neural Network and Genetic Algorithm Method, J. Chromatogr. Sci., 53 (2015) 1801-1807.

[38] F. Nasiri Azad, M. Ghaedi, K. Dashtian, S. Hajati, A. Goudarzi, M. Jamshidi, Enhanced simultaneous removal of malachite green and safranin $\mathrm{O}$ by $\mathrm{ZnO}$ nanorod-loaded activated carbon: modeling, optimization and adsorption isotherms, New J. Chem., 39 (2015) 7998-8005.

[39] F.N. Azad, M. Ghaedi, A. Asfaram, A. Jamshidi, G. Hassani, A. Goudarzi, M.H.A. Azqhandi, A. Ghaedi, Optimization of the process parameters for the adsorption of ternary dyes by $\mathrm{Ni}$ doped $\mathrm{FeO}(\mathrm{OH})-\mathrm{NWs}-\mathrm{AC}$ using response surface methodology and an artificial neural network, RSC Adv., 6 (2016) 19768-19779.

[40] M. Ghaedi, E. Alam barakat, A. Asfaram, B. Mirtamizdoust, A.A. Bazrafshan, S. Hajati, Efficient adsorption of Europhtal onto activated carbon modified with ligands (1E,2E)-1,2-bis(pyridin-4-ylmethylene)hydrazine (M) and (1E,2E)-1,2-bis(pyridin-3-ylmethylene)hydrazine (SCH-4); response surface methodology, RSC Adv., 5 (2015) 42376-42387.

[41] P. Izadiyan, B. Hemmateenejad, Multi-response optimization of factors affecting ultrasonic assisted extraction from Iranian basil using central composite design, Food Chem., 190 (2016) 864-870.

[42] A. Asfaram, M. Ghaedi, S. Hajati, A. Goudarzi, Ternary dye adsorption onto $\mathrm{MnO}_{2}$ nanoparticle-loaded activated carbon: derivative spectrophotometry and modeling, RSC Adv., 5 (2015) 72300-72320.

[43] A. Asfaram, M. Ghaedi, M.H.A. Azqhandi, A. Goudarzi, M. Dastkhoon, Statistical experimental design, least squares-support vector machine (LS-SVM) and artificial neural network (ANN) methods for modeling the facilitated adsorption of methylene blue dye, RSC Adv., 6 (2016) 40502-40516. 
Table 1. Independent variables and levels used for response surface design.

\begin{tabular}{|l|l|c|c|c|c|c|}
\hline \multirow{2}{*}{ Factors } & \multirow{2}{*}{ Symbol (unit) } & \multicolumn{5}{|c|}{ Levels } \\
\cline { 3 - 8 } & & Lowest $(-\alpha)$ & Low (-1) & Central $(0)$ & High $(+1)$ & Highest $(+\alpha)$ \\
\hline $\mathrm{pH}$ & $\mathrm{A}(-)$ & 4.0 & 5.0 & 6.0 & 7.0 & 8.0 \\
\hline Adsorbent mass $(\mathrm{mg})$ & $\mathrm{B}(\mathrm{mg})$ & 0.5 & 1.0 & 1.5 & 2.0 & 2.5 \\
\hline Ultrasound time (min) & $\mathrm{C}(\mathrm{min})$ & 2 & 4 & 6 & 8 & 10 \\
\hline Eluent volume & $\mathrm{D}(\mu \mathrm{L})$ & 120 & 150 & 180 & 210 & 240 \\
\hline
\end{tabular}


Table 2. CCD matrix of independent variables and their corresponding experimental and predicted extraction percent of safranin $\mathrm{O}$.

\begin{tabular}{|c|c|c|c|c|c|c|c|}
\hline \multirow[t]{2}{*}{ Experiment } & \multicolumn{4}{|c|}{ Actual values of variables } & \multicolumn{3}{|c|}{ Response (ER\% SO) } \\
\hline & A & $\mathrm{B}$ & $\mathrm{C}$ & $\mathrm{D}$ & Experimental & Predicted & Residual \\
\hline 1 & 7.0 & 1.0 & 4 & 150 & 87.674 & 86.728 & 0.946 \\
\hline 2 & 6.0 & 1.5 & 6 & 180 & 92.536 & 92.425 & 0.111 \\
\hline 3 & 6.0 & 1.5 & 6 & 120 & 91.618 & 91.202 & 0.416 \\
\hline 4 & 7.0 & 1.0 & 8 & 210 & 92.994 & 93.306 & -0.312 \\
\hline 5 & 6.0 & 1.5 & 6 & 180 & 92.719 & 92.425 & 0.294 \\
\hline 6 & 5.0 & 1.0 & 4 & 150 & 82.813 & 83.805 & -0.992 \\
\hline 7 & 5.0 & 2.0 & 4 & 150 & 77.402 & 77.193 & 0.209 \\
\hline 8 & 6.0 & 2.5 & 6 & 180 & 82.63 & 82.924 & -0.294 \\
\hline 9 & 7.0 & 1.0 & 4 & 210 & 88.959 & 88.523 & 0.436 \\
\hline 10 & 5.0 & 1.0 & 4 & 210 & 74.65 & 74.200 & 0.450 \\
\hline 11 & 6.0 & 1.5 & 6 & 180 & 92.352 & 92.425 & -0.073 \\
\hline 12 & 7.0 & 1.0 & 8 & 150 & 95.948 & 97.459 & -1.511 \\
\hline 13 & 5.0 & 1.0 & 6 & 210 & 73.916 & 74.771 & -0.855 \\
\hline 14 & 6.0 & 1.5 & 6 & 240 & 81.097 & 81.312 & -0.215 \\
\hline 15 & 5.0 & 2.0 & 8 & 150 & 79.42 & 79.955 & -0.535 \\
\hline 16 & 6.0 & 1.5 & 6 & 180 & 91.343 & 92.425 & -1.082 \\
\hline 17 & 6.0 & 1.5 & 6 & 180 & 92.077 & 92.425 & -0.348 \\
\hline 18 & 7.0 & 2.0 & 4 & 210 & 87.95 & 88.698 & -0.748 \\
\hline 19 & 4.0 & 1.5 & 6 & 180 & 59.608 & 59.351 & 0.257 \\
\hline 20 & 7.0 & 2.0 & 8 & 210 & 91.985 & 91.092 & 0.893 \\
\hline 21 & 6.0 & 1.5 & 2 & 180 & 83.757 & 84.773 & -1.016 \\
\hline 22 & 5.0 & 2.0 & 8 & 210 & 67.221 & 68.270 & -1.049 \\
\hline 23 & 7.0 & 2.0 & 4 & 150 & 83.364 & 83.035 & 0.329 \\
\hline 24 & 7.0 & 2.0 & 8 & 150 & 91.252 & 91.377 & -0.125 \\
\hline 25 & 5.0 & 2.0 & 4 & 210 & 72.868 & 71.456 & 1.412 \\
\hline 26 & 6.0 & 1.5 & 6 & 180 & 93.728 & 92.425 & 1.303 \\
\hline 27 & 6.0 & 0.5 & 6 & 180 & 92.246 & 91.750 & 0.496 \\
\hline 28 & 5.0 & 1.0 & 8 & 150 & 89.601 & 88.956 & 0.645 \\
\hline 29 & 6.0 & 1.5 & 6 & 180 & 92.436 & 92.425 & 0.011 \\
\hline 30 & 6.0 & 1.5 & 10 & 180 & 93.322 & 92.319 & 1.003 \\
\hline 31 & 8.0 & 1.5 & 6 & 180 & 85.041 & 85.096 & -0.055 \\
\hline
\end{tabular}


Table 3. Analysis of variance (ANOVA) for the fitted quadratic polynomial model for optimization of SO extraction.

\begin{tabular}{|c|c|c|c|c|c|c|}
\hline Source & Sums of squares & Degree of freedom & Mean squares & F-value & \multicolumn{2}{|c|}{ p-value (Prob > F) } \\
\hline Model & 2310.1 & 14 & 165.01 & 160.40 & $<0.0001$ & $*$ \\
\hline A & 978.55 & 1 & 978.55 & 951.25 & $<0.0001$ & $*$ \\
\hline B & 115.01 & 1 & 115.01 & 111.80 & $<0.0001$ & $*$ \\
\hline $\mathrm{C}$ & 78.874 & 1 & 78.874 & 76.673 & $<0.0001$ & $*$ \\
\hline $\mathrm{D}$ & 144.41 & 1 & 144.41 & 140.39 & $<0.0001$ & * \\
\hline $\mathrm{AB}$ & 8.3222 & 1 & 8.3222 & 8.0900 & 0.01172 & $*$ \\
\hline $\mathrm{AC}$ & 27.694 & 1 & 27.694 & 26.922 & $<0.0001$ & $*$ \\
\hline $\mathrm{AD}$ & 126.91 & 1 & 126.91 & 123.37 & $<0.0001$ & $*$ \\
\hline $\mathrm{BC}$ & 5.0769 & 1 & 5.0769 & 4.9353 & 0.04109 & $*$ \\
\hline $\mathrm{BD}$ & 14.609 & 1 & 14.609 & 14.202 & 0.00168 & $*$ \\
\hline $\mathrm{CD}$ & 31.468 & 1 & 31.468 & 30.590 & $<0.0001$ & $*$ \\
\hline $\mathrm{A}^{2}$ & 726.90 & 1 & 726.90 & 706.62 & $<0.0001$ & $*$ \\
\hline $\mathrm{B}^{2}$ & 46.111 & 1 & 46.111 & 44.825 & $<0.0001$ & $*$ \\
\hline $\mathrm{C}^{2}$ & 26.818 & 1 & 26.818 & 26.070 & 0.00011 & * \\
\hline $\mathrm{D}^{2}$ & 67.775 & 1 & 67.775 & 65.884 & $<0.0001$ & * \\
\hline Residual & 16.459 & 16 & 1.0287 & & & \\
\hline Lack of Fit & 13.372 & 10 & 1.3372 & 2.5989 & 0.12732 & ** \\
\hline Pure Error & 3.0872 & 6 & 0.51453 & & & \\
\hline Cor Total & 2326.5 & 30 & & & & \\
\hline $\mathrm{R}^{2}$ & Adj-R ${ }^{2}$ & & & & quate Prec & \\
\hline 0.9929 & 0.9867 & & & & 54.014 & \\
\hline
\end{tabular}

* Significant.

** Not significant. 
Table. 4. Comparison of 1-15 neurons in the hidden layer for extraction efficiency by ANN model development with the Levenberg-Marquardt algorithm for preconcentration and determination of SO.

\begin{tabular}{|l|l|l|l|l|l|l|l|l|}
\hline Neurons & $\mathrm{R}_{\text {train }}^{2}$ & $\mathrm{R}_{\text {test }}^{2}$ & $\mathrm{R}_{\text {validation }}^{2}$ & $\mathrm{R}^{2}$ & $\mathrm{MSE}_{\text {train }}$ & $\mathrm{MSE}_{\text {test }}$ & $\mathrm{MSE}_{\text {validation }}$ & $\mathrm{MSE}$ \\
\hline 1 & 0.933018 & 0.918241 & 0.913803 & 0.923737 & 10.0779 & 12.27129 & 14.72252 & 11.07052 \\
\hline 2 & 0.975097 & 0.858537 & 0.983397 & 0.974884 & 3.910377 & 2.424262 & 4.535992 & 3.785466 \\
\hline 3 & 0.983102 & 0.975507 & 0.979073 & 0.979936 & 2.66566 & 4.385099 & 4.264996 & 3.147418 \\
\hline 4 & 0.95098 & 0.752418 & 0.948011 & 0.939401 & 7.957128 & 11.97373 & 14.08372 & 9.429527 \\
\hline 5 & 0.999389 & 0.990067 & 0.99126 & 0.995911 & 0.099671 & 1.854985 & 2.12348 & 0.648253 \\
\hline 6 & 0.99943 & 0.998408 & 0.998739 & 0.998886 & 0.098101 & 0.603087 & 0.115799 & 0.173974 \\
\hline 7 & 0.999233 & 0.969813 & 0.998071 & 0.993437 & 0.10912 & 6.205884 & 0.448885 & 1.043455 \\
\hline 8 & 0.996283 & 0.996887 & 0.990607 & 0.994829 & 1.205446 & 0.549324 & 1.617628 & 1.170035 \\
\hline 9 & 0.999452 & 0.99915 & 0.999337 & 0.999336 & 0.089323 & 0.138593 & 0.108604 & 0.099643 \\
\hline 10 & 0.998699 & 0.986223 & 0.994588 & 0.98998 & 0.135729 & 8.842882 & 8.869638 & 2.667496 \\
\hline 11 & 0.998098 & 0.996741 & 0.993644 & 0.996524 & 0.336667 & 0.228297 & 1.97769 & 0.559149 \\
\hline 12 & 0.99849 & 0.9327 & 0.923563 & 0.980338 & 0.299694 & 8.600074 & 11.91352 & 3.190465 \\
\hline 13 & 0.999236 & 0.906145 & 0.878618 & 0.965487 & 0.107634 & 17.67611 & 17.6893 & 5.210074 \\
\hline 14 & 0.999211 & 0.926304 & 0.922563 & 0.941593 & 0.095877 & 22.98083 & 40.3452 & 9.260531 \\
\hline 15 & 0.928914 & 0.934976 & 0.968736 & 0.932931 & 13.07545 & 11.26508 & 6.094459 & 11.79929 \\
\hline
\end{tabular}


Table 5. The weight and bias of trained ANN for predicting the extraction of SO dye.

\begin{tabular}{|l|l|l|l|l|l|l|}
\hline $\mathrm{w} 1$ & & $\mathrm{w} 2$ & $\mathrm{~b} 1$ & $\mathrm{~b} 2$ \\
\hline 1.2485490 & -3.9314979 & -3.817844 & 1.5531901 & 0.00116399 & -0.155 & 0.0872 \\
\hline 3.92957743 & 4.7907632 & 1.1705057 & 1.6146074 & -0.05529279 & -6.3302 & \\
\hline 3.01075718 & -4.0399144 & 1.83234730 & 2.9846349 & -0.10375259 & -2.9514 & \\
\hline 1.31982239 & 3.00215787 & -3.3184370 & -2.6252863 & -0.12428062 & 0.7856 & \\
\hline-3.2083859 & -3.7331529 & -4.5483728 & 1.9366376 & -0.19341471 & 1.8433 & \\
\hline-1.3496414 & 0.3548539 & -3.8888162 & -4.2049562 & -0.13064912 & 2.8859 & \\
\hline 1.4050600 & -0.5649643 & -5.7394318 & -0.4829760 & -0.05423904 & 3.2829 & \\
\hline 0.0056189 & -2.0426111 & -2.4841625 & -6.3500128 & 0.062040953 & 2.3076 & \\
\hline-5.310292 & 0.5615058 & 1.786162 & 2.1490475 & -0.47518742 & -0.8281 & \\
\hline
\end{tabular}


Table 6. The comparison between optimum conditions of CCD and ANN-GA models.

\begin{tabular}{|c|c|c|c|c|c|c|}
\hline \multirow[b]{2}{*}{ Approach } & \multicolumn{4}{|c|}{ Variables } & \multicolumn{2}{|l|}{ ER\% } \\
\hline & $\mathrm{pH}$ & Amount of adsorbent (mg) & Ultrasound time (min) & Eluent volume $(\mu \mathrm{L})$ & Experimental (RSD, $\mathrm{N}=5)$ & Predicted \\
\hline $\mathrm{CCD}$ & 7.0 & 1.5 & 8 & 180 & $96.12(2.4)$ & 95.47 \\
\hline ANN-GA & 6.5 & 1.1 & 10 & 150 & $99.92(1.8)$ & 99.74 \\
\hline
\end{tabular}


Table 7. Analytical characteristics of the proposed method.

\begin{tabular}{|c|c|}
\hline Quantitative analysis & \\
\hline Sample volume $(\mathrm{mL})$ & 10 \\
\hline Volume of eluent $(\mu \mathrm{L})$ & 150 \\
\hline Regression equation before preconcentration & $y=0.0626 x+0.0014 ; R^{2}=0.9999$ \\
\hline Regression equation after preconcentration & $y=7.7996 x+0.0747 ; R^{2}=0.9972$ \\
\hline Linear range $\left(\mathrm{ng} \mathrm{mL}^{-1}\right)$ & $25-3500$ \\
\hline Limit of detection $\left(\mathrm{ng} \mathrm{mL}^{-1}\right)$ & 6.3 \\
\hline Repeatability (RSD, \%) $\left(\mathrm{n}=5,0.5 \mu \mathrm{g} \mathrm{mL}^{-1}\right)$ & 2.8 \\
\hline Limit of quantification (LOQ) $\left(\mathrm{ng} \mathrm{mL}^{-1}\right)$ & 17.5 \\
\hline Average extraction recovery & $95.60 \%$ \\
\hline Preconcentration factor & 66.67 \\
\hline Enrichment factor & 124.59 \\
\hline
\end{tabular}


Table 8. Tolerance limits of interfering species in the determination of $500 \mathrm{ng} \mathrm{mL}^{-1} \mathrm{SO}(\mathrm{N}=3)$.

\begin{tabular}{|c|c|c|c|}
\hline Interference & Added as & Tolerance ratio $\left(\mathrm{mg} \mathrm{L}^{-1}\right)$ & $\mathrm{ER} \%(\mathrm{RSD})$ \\
\hline $\mathrm{Na}^{+}$ & $\mathrm{NaNO}_{3}$ & 500 & $96.32(1.7)$ \\
\hline $\mathrm{Ca}^{2+}$ & $\mathrm{Ca}\left(\mathrm{NO}_{3}\right)_{2}$ & 500 & $97.22(0.9)$ \\
\hline $\mathrm{SO}^{4-}$ & $\mathrm{Ca}\left(\mathrm{NO}_{3}\right)_{2}$ & 500 & $96.32(1.6)$ \\
\hline $\mathrm{Mg}^{2+}$ & $\mathrm{Mg}\left(\mathrm{NO}_{3}\right)_{2}$ & 500 & $95.45(1.3)$ \\
\hline $\mathrm{I}^{-}$ & $\mathrm{KI}$ & 500 & $96.11(2.0)$ \\
\hline $\mathrm{Br}^{-}$ & $\mathrm{KBr}$ & 500 & $97.22(1.4)$ \\
\hline $\mathrm{NH}_{4}^{+}$ & $\mathrm{NH}_{4} \mathrm{NO}_{3}$ & 500 & $97.95(1.5)$ \\
\hline $\mathrm{Cl}^{-}$ & $\mathrm{KCl}$ & 500 & $95.76(1.0)$ \\
\hline $\mathrm{NO}^{3-}$ & $\mathrm{KNO}_{3}$ & 500 & $97.25(0.8)$ \\
\hline $\mathrm{K}^{+}$ & $\mathrm{KNO}_{3}$ & 500 & $97.12(1.3)$ \\
\hline $\mathrm{Ba}^{2+}$ & $\mathrm{Ba}\left(\mathrm{NO}_{3}\right)_{2}$ & 500 & $96.35(1.2)$ \\
\hline $\mathrm{Ag}^{+}$ & $\mathrm{AgNO}_{3}$ & 200 & $95.04(1.5)$ \\
\hline $\mathrm{Fe}^{3+}$ & $\mathrm{FeCl}_{3}$ & 200 & $94.76(0.7)$ \\
\hline $\mathrm{Co}^{2+}$ & $\mathrm{Co}\left(\mathrm{NO}_{3}\right)_{2}$ & 200 & $95.23(1.8)$ \\
\hline $\mathrm{Ni}^{2+}$ & $\mathrm{Ni}\left(\mathrm{NO}_{3}\right)_{2}$ & 150 & $96.54(2.3)$ \\
\hline $\mathrm{Cr}^{2+}$ & $\mathrm{Cr}\left(\mathrm{NO}_{3}\right)_{2}$ & 150 & $95.01(2.1)$ \\
\hline $\mathrm{Pb}^{2+}$ & $\mathrm{Pb}\left(\mathrm{NO}_{3}\right)_{2}$ & 150 & $96.78(1.4)$ \\
\hline $\mathrm{Cu}^{2+}$ & $\mathrm{Cu}\left(\mathrm{NO}_{3}\right)_{2}$ & 150 & $97.76(2.1)$ \\
\hline Ponceau 4R & - & 100 & $96.75(1.4)$ \\
\hline Carmoisine & - & 100 & $97.21(1.6)$ \\
\hline Sunset Yellow FCF & - & 100 & $98.00(1.7)$ \\
\hline Methylene blue & - & 100 & $95.45(2.3)$ \\
\hline Tartrazine & - & 100 & $94.90(2.8)$ \\
\hline Allura Red AC & - & 100 & $95.21(1.4)$ \\
\hline
\end{tabular}


Table 9. Extraction recoveries and RSD in water and industry wastewater samples at spiked level by USA-DSPMEUV method ( $\mathrm{N}=5)$.

\begin{tabular}{|c|c|c|c|}
\hline Samples & SO added $\left(\mathrm{ng} \mathrm{mL} L^{-1}\right)$ & SO Found $\left(\mu \mathrm{g} \mathrm{mL}^{-1}\right)$ & $\mathrm{ER} \%$ (RSD) \\
\hline Wastewater $^{a}$ & 500 & 488.20 & $97.64(1.6)$ \\
\hline Tap water ${ }^{\mathrm{a}}$ & 500 & 497.05 & $99.41(0.9)$ \\
\hline Wastewater ${ }^{b}$ & 500 & 474.00 & $94.80(2.7)$ \\
\hline Wastewater $^{c}$ & 500 & 466.35 & $93.27(1.8)$ \\
\hline Wastewater $^{d}$ & 500 & 471.80 & $94.36(2.4)$ \\
\hline
\end{tabular}

${ }^{\mathrm{a}}$ Refinery in Gachsaran city

${ }^{\mathrm{b}}$ Sugar factory in Yasouj city

${ }^{\mathrm{c}}$ Hadaf Textile Industries Company Esfahan city

${ }^{\mathrm{d}}$ Kimia Polyester Qom Company 

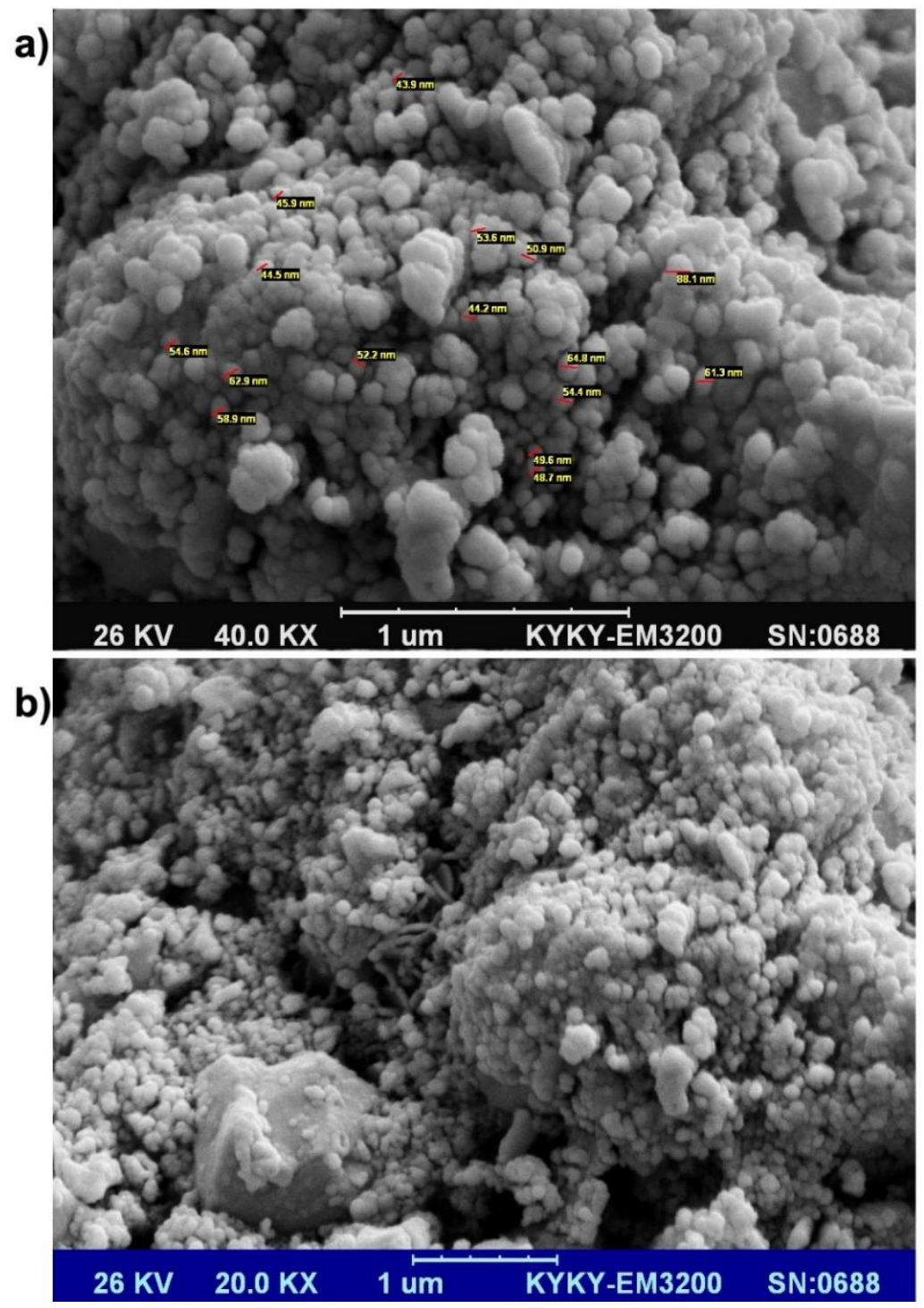

Fig. 1. (a) SEM images of $\mathrm{Fe}_{2} \mathrm{O}_{3}$-NPs and (b) $\mathrm{Fe}_{2} \mathrm{O}_{3}$-NPs-AC. 


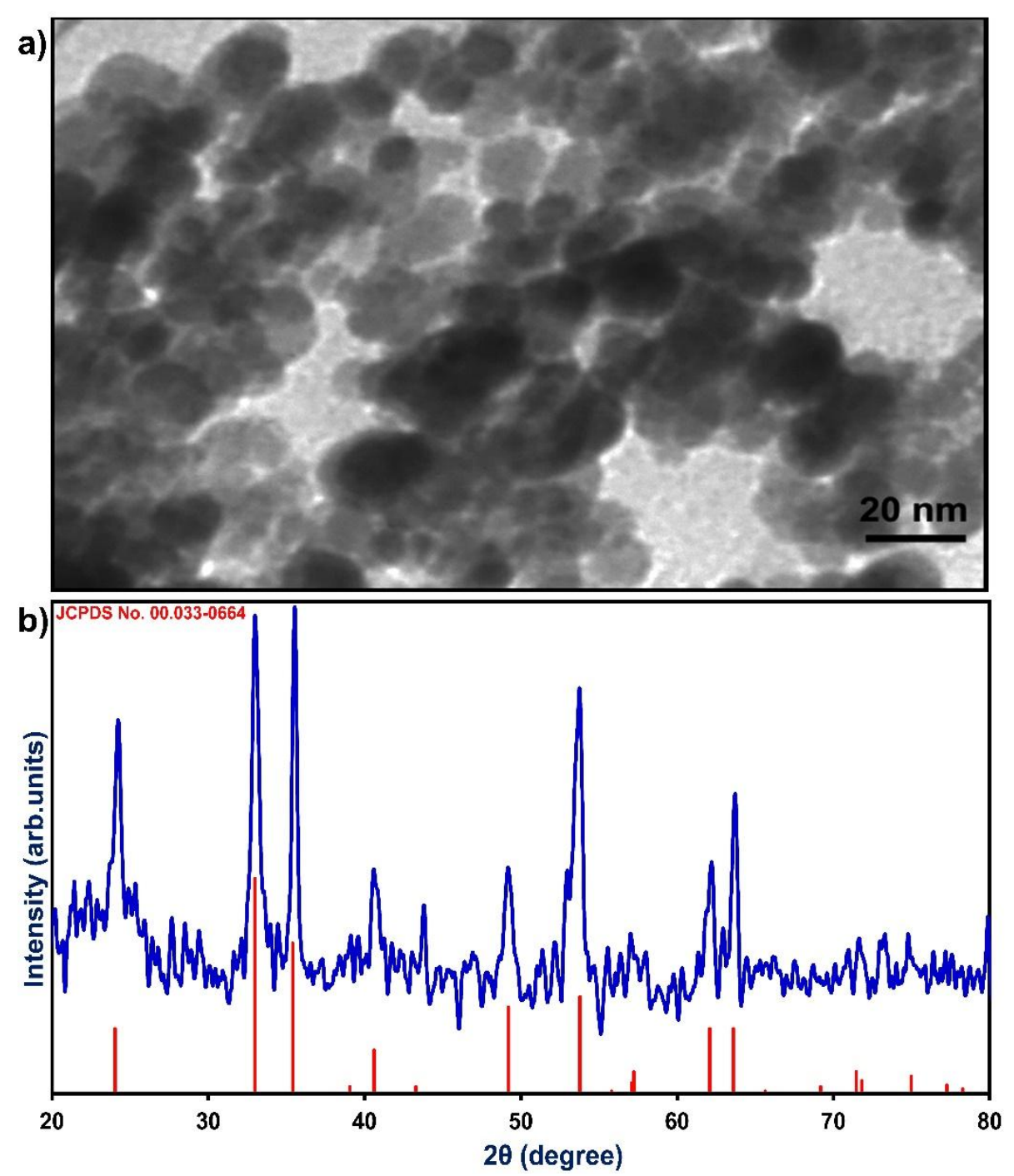

Fig. 2. a) TEM image of $\mathrm{Fe}_{2} \mathrm{O}_{3}$-NPs and b) XRD pattern of the $\mathrm{Fe}_{2} \mathrm{O}_{3}$-NPs-AC. 


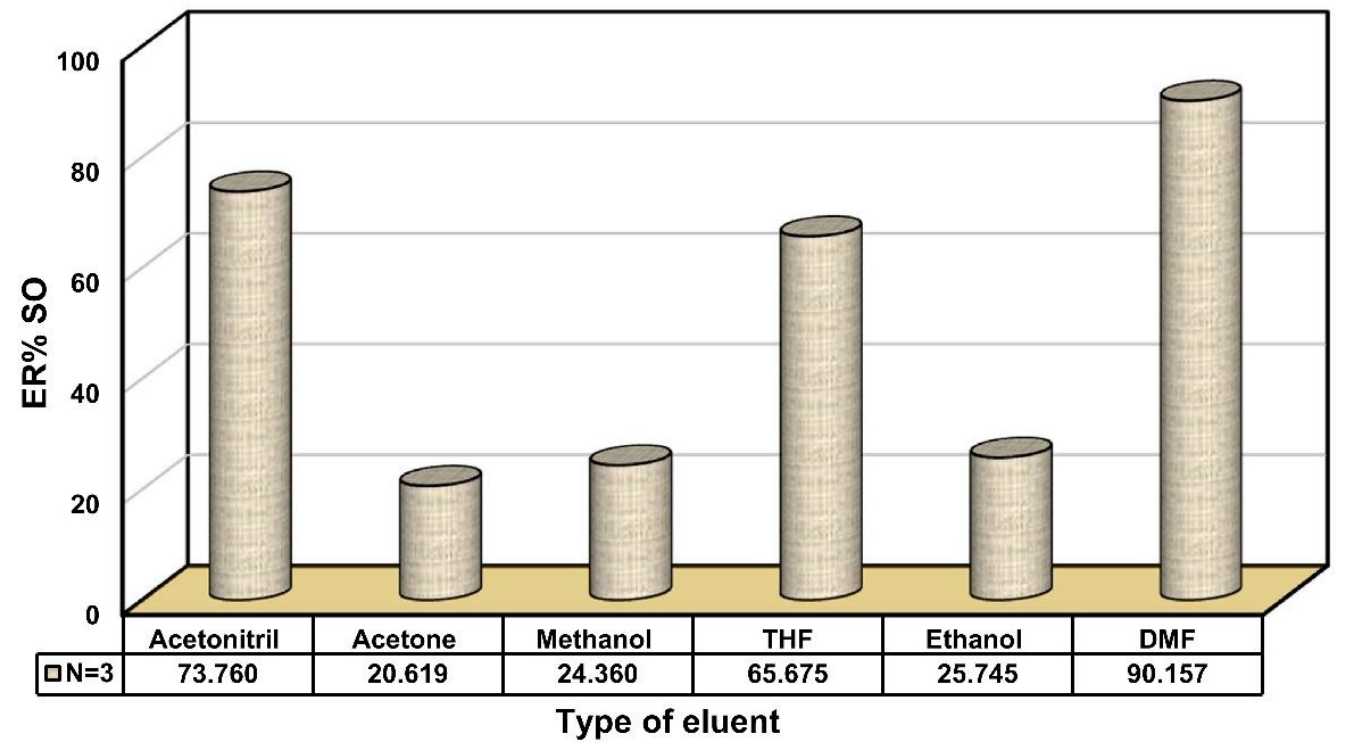

Fig. 3. The effect of the type of extraction solvent on the extraction recovery of SO using the proposed USANSPME method. Extraction conditions: volume of extraction solution: $200 \mu \mathrm{L} ; \mathrm{pH}$ of extraction solution $=6.0$; ultrasound time: $6 \mathrm{~min}$; volume of sample: $10.0 \mathrm{~mL}$ and $1.5 \mathrm{mg}$ adsorbent mass. 

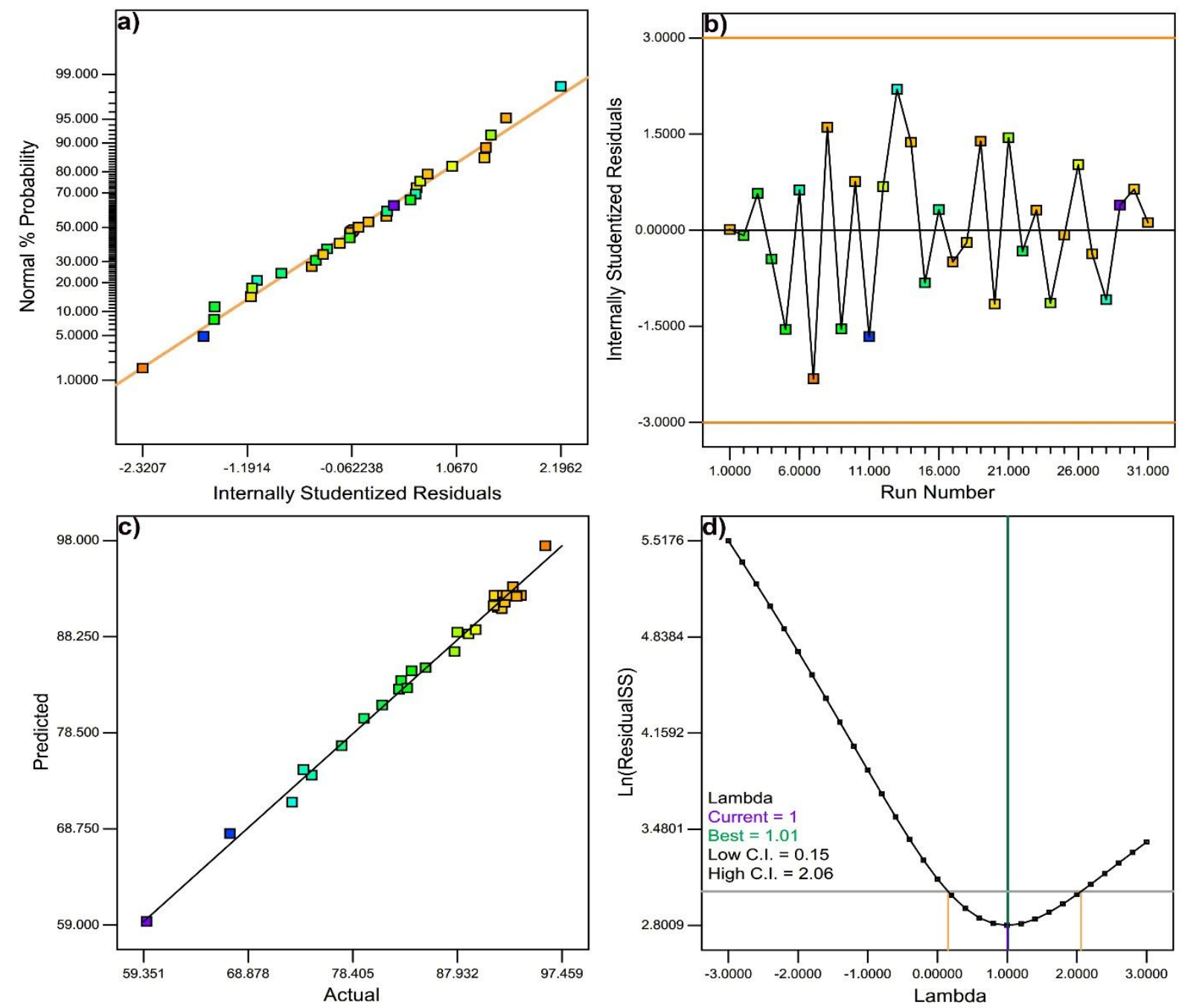

Fig. 4. a) Normal \% probability plot of the residuals, b) Plot of residuals versus run number, c) plot showing model predicted value versus actual value and d) The Box-Cox plot for extraction yield; pink color lines represent the upper (2.06) and the lower (0.0.15) limits of the 95\% confidence interval calculated for the Box-Cox lambda value, the blue and green lines represent the current (1) and the best (1.01) lambda values, respectively. A horizontal line is drawn for the Ln (Residual SS) value corresponding to confidence limits for SO extract yields. 

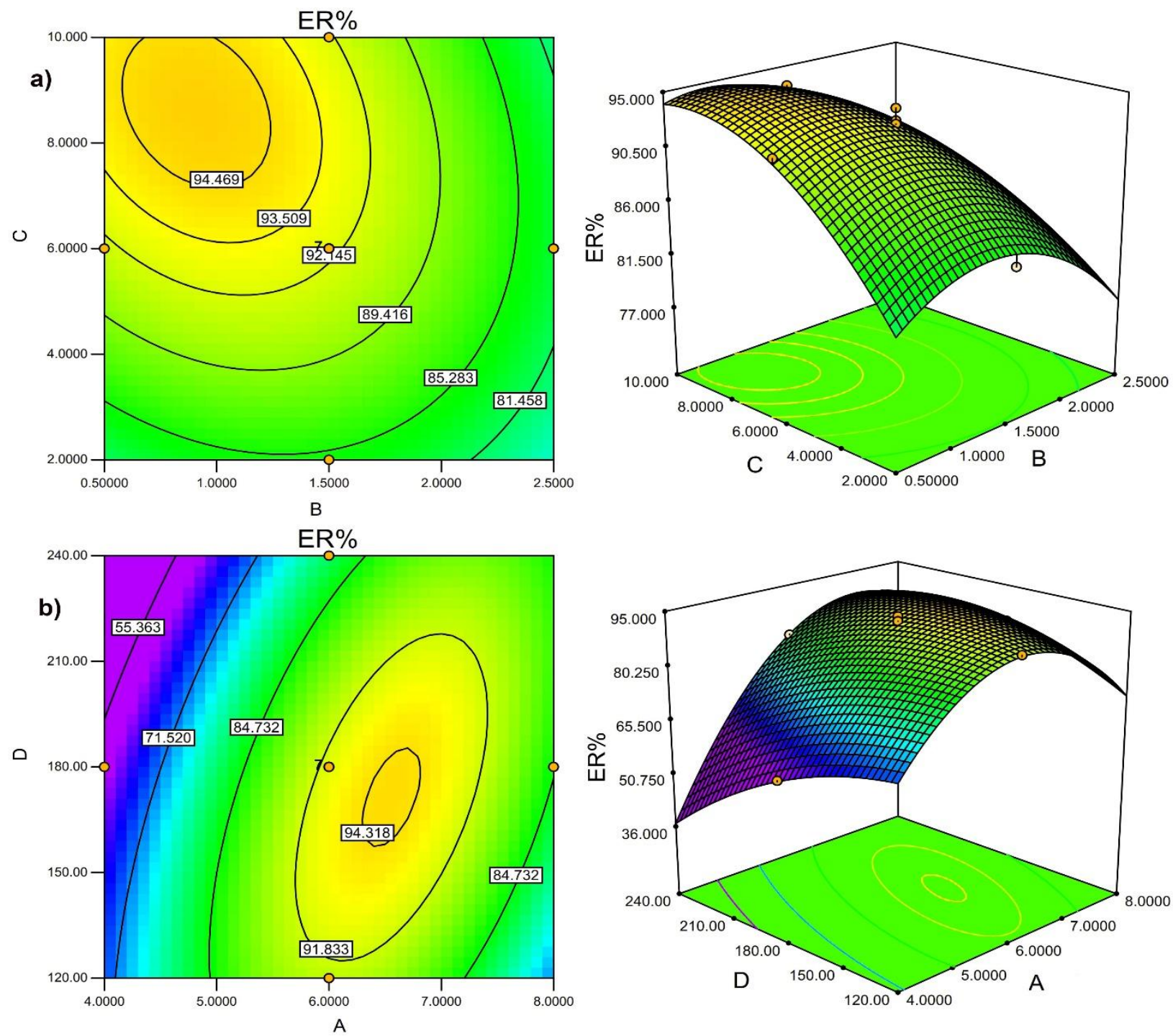

Fig. 5. Response surface plots showing effects of variables (A: $\mathrm{pH}, \mathrm{B}$ : adsorbent mass (mg), C: ultrasound time $(\min )$ and $\mathrm{D}$ : eluent volume $(\mu \mathrm{L}))$ on the extraction yield of melatonin. 
B: Adsorbent mass
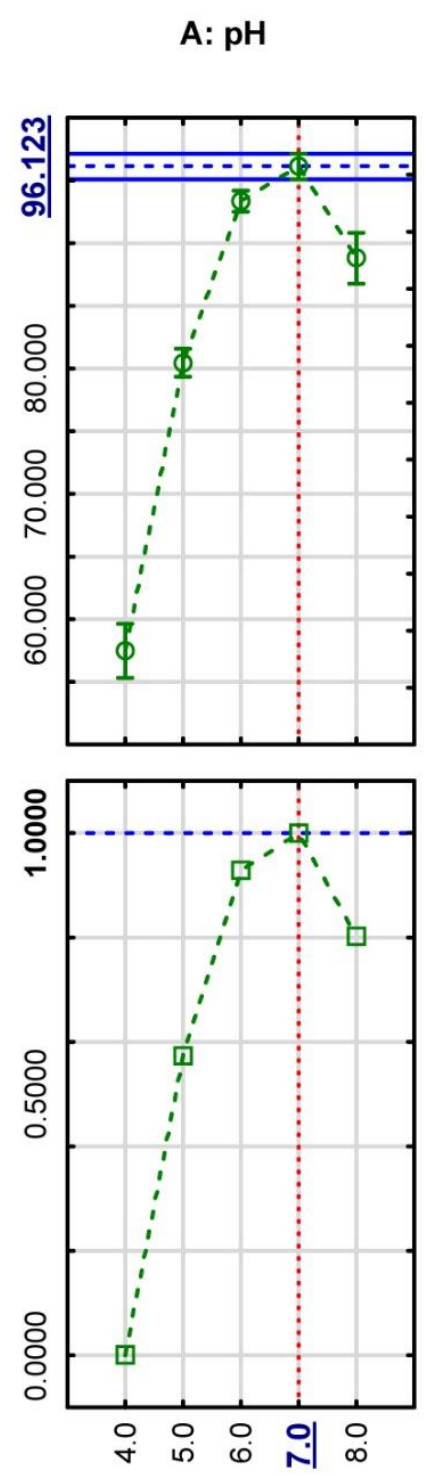
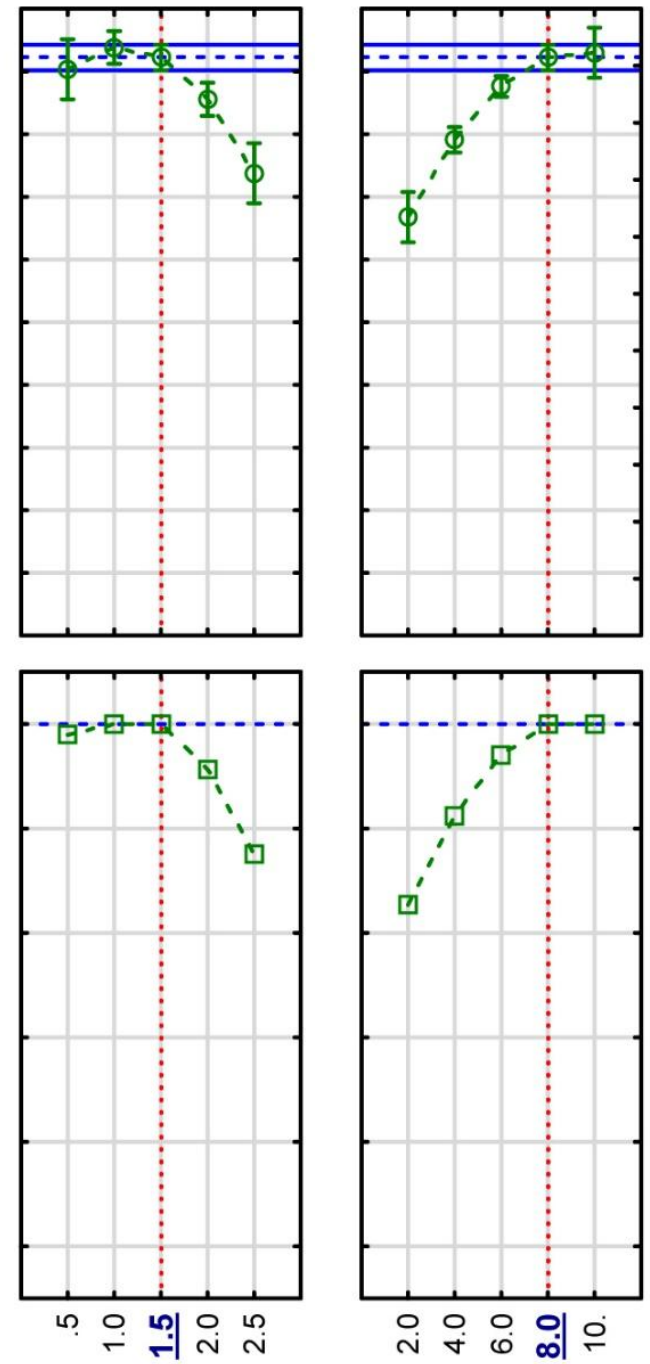

C: Ultrasound time

(min)

D: Eluent volume

$(\mu \mathrm{L})$

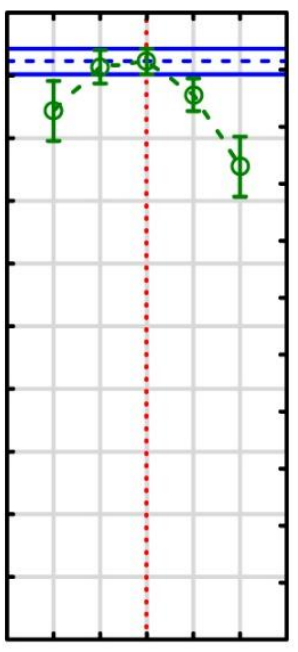

Desirability
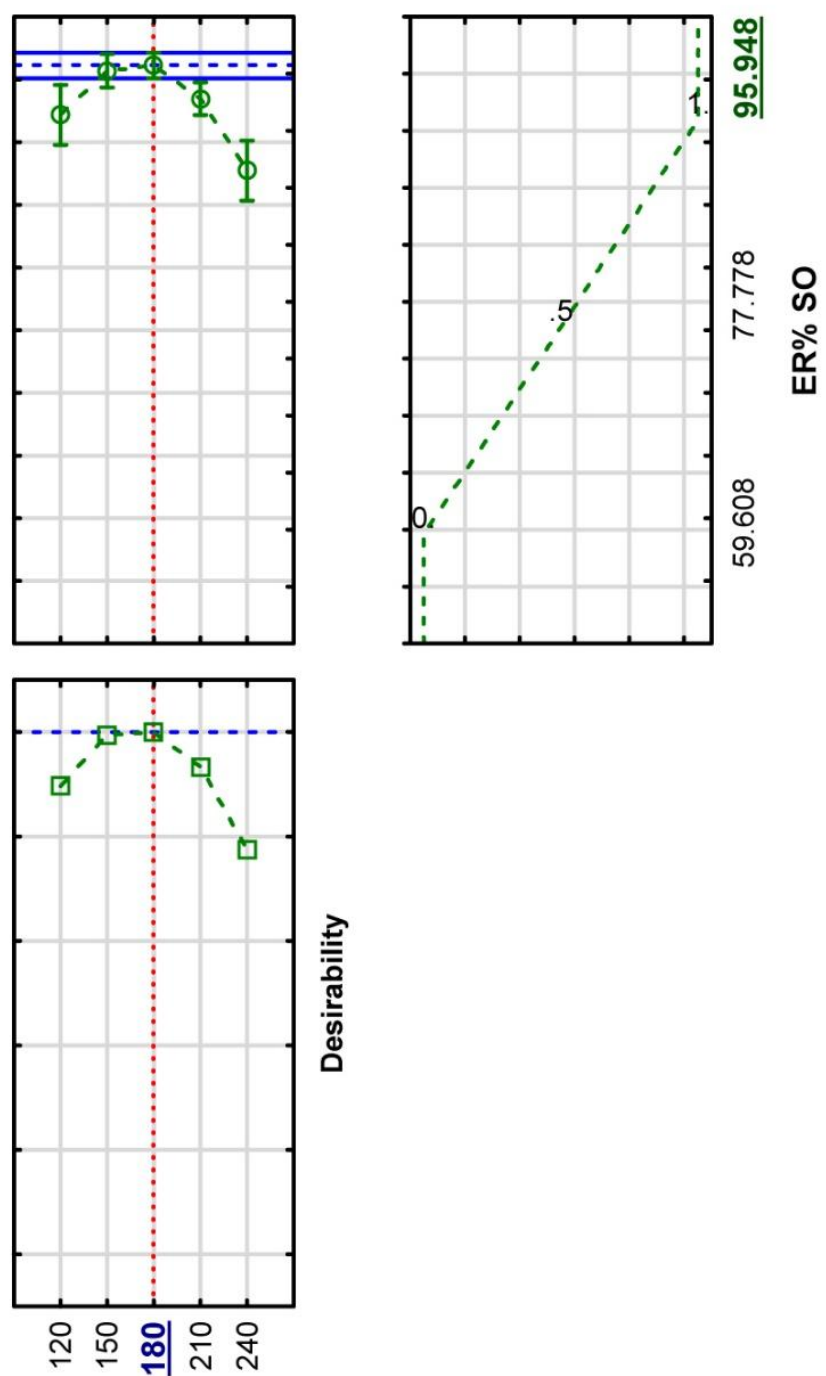

Fig. 6. Profiles for predicated values and desirability function for ER\% of SO. Dashed line indicated current values after optimization. 

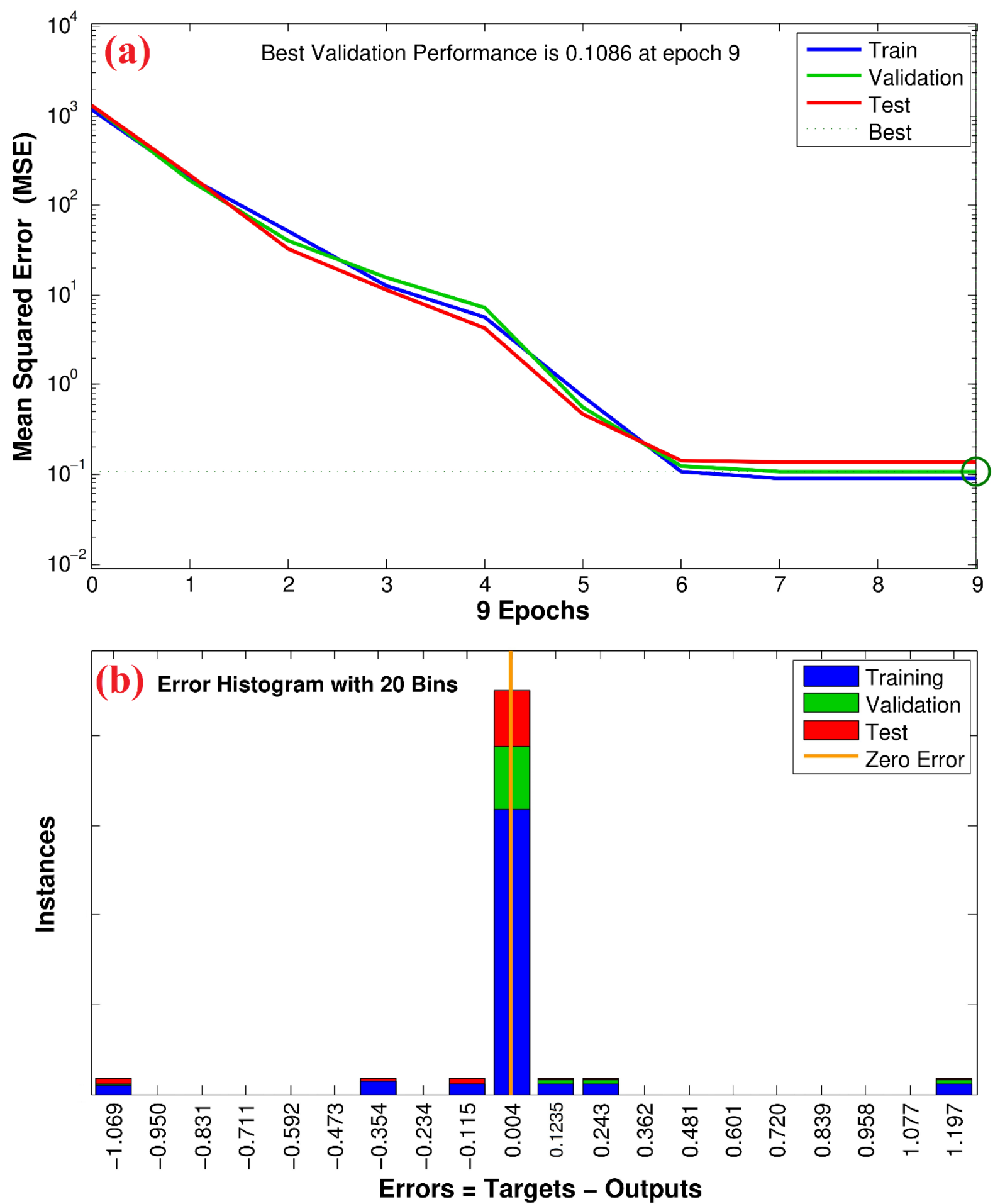

Fig. 7. MSE versus the number of epochs (a) and plot of Error Histogram (b) for removal percentage of SO dye by $\mathrm{Fe}_{2} \mathrm{O}_{3}$-NPs-AC. 

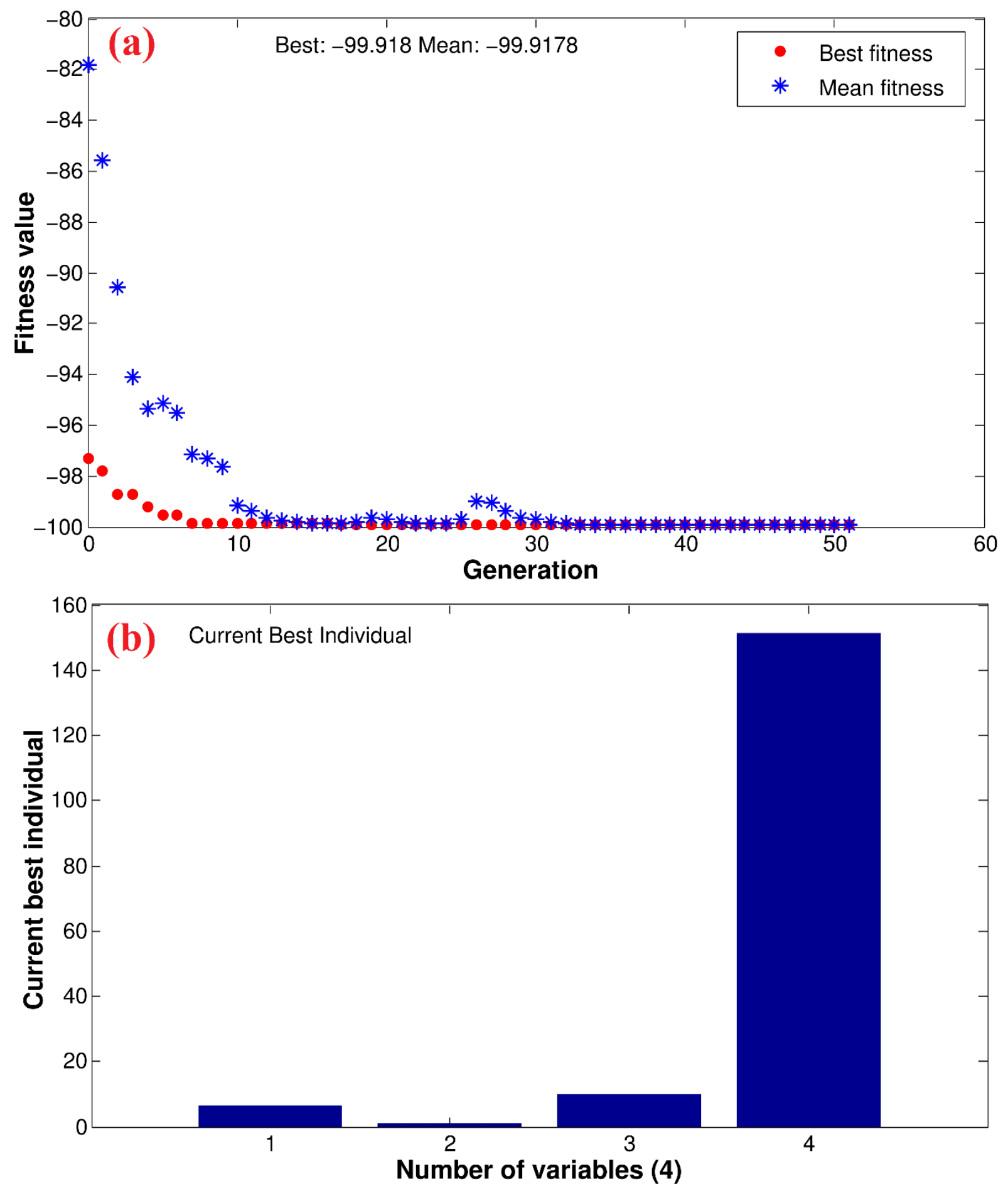

Fig. 8. Plots of best fitness and best individual for extraction of SO dye by ANN-GA method. 

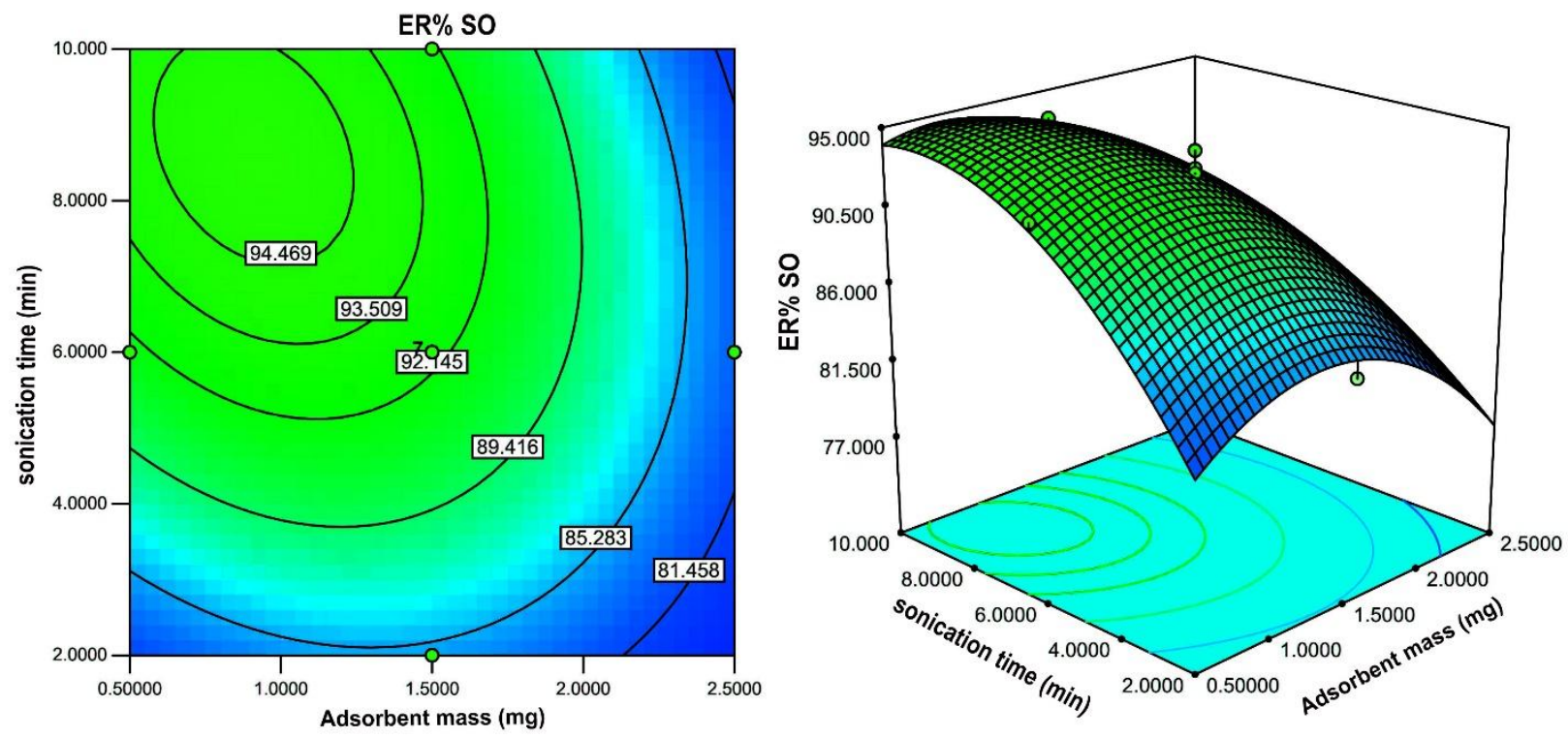

\section{Graphical abstract}

